\title{
Dry Deposition from Sahara Sources Regions of Western Africa
}

\author{
B. Douaiba, ${ }^{1}$ A. Azzi, ${ }^{1}$ A. Khorsi, ${ }^{2}$ and A. Benlefki ${ }^{3}$ \\ ${ }^{1}$ Faculty of Mechanical Engineering, University of Sciences and Technology of Oran, Oran, Algeria \\ ${ }^{2}$ School in Science and Technology of Oran, Algeria \\ ${ }^{3}$ Algerian Petroleum Institute IAP, Arzew, Oran, Algeria \\ Correspondence should be addressed to B. Douaiba; hakou_djawed2005@yahoo.fr
}

Received 14 November 2013; Accepted 26 January 2014; Published 17 March 2014

Academic Editor: Gianluigi de Gennaro

Copyright (c) 2014 B. Douaiba et al. This is an open access article distributed under the Creative Commons Attribution License, which permits unrestricted use, distribution, and reproduction in any medium, provided the original work is properly cited.

\begin{abstract}
Sahara dust storms during March 2004 have attracted much attention from the dust-research community due to their intensity, wide coverage, and endurance. In the present work, the dry deposition mechanisms of mineral dust are analysed during an event on the 3 March 2004 over the Northwest African coast. This particular case was chosen based on the strong dry removal that occurred, rendering it ideal for examining the deposition processes. The simulation of synoptic conditions and dry deposition of four dust particles including clay, small silt, large silt, and sand was performed with Eta model, coupled with a desert dust cycle module. The results have been compared with surface data from weather stations in North Africa, data of dry metals from stations located in Gran Canaria, and various satellite images such as European Organization for the Exploitation of Meteorological Satellites and Moderate Resolution Imaging Spectroradiometer for the period in question.
\end{abstract}

\section{Introduction}

The global source strength of mineral aerosol is currently estimated to a value between 1000 and $5000 \mathrm{Mt} \cdot \mathrm{yr}^{-1}$, for example, $[1,2]$, more than half generally originates over West Africa [3-5], compared to several hundred $\mathrm{Mt} \cdot \mathrm{yr}^{-1}$ for sulphate aerosol, for example, [6] that deposited over Atlantic Ocean as well as the Canary Islands [7]. Dry deposition from Sahara sources regions of western Africa containing compounds such as sulphate, nitrate, or radioactive substances has been studied worldwide over the last 30 years, and there remains a discrepancy between both measurement results and model predictions.

The presence of some metals such as $\mathrm{Al}, \mathrm{Fe}, \mathrm{Co}$, and $\mathrm{Mn}$, in dust may significantly modify the marine biochemistry and may change the phytoplankton communities resulting in fast growth rates leading to blooms [8], after deposition to Ocean waters [9].

Dry deposition is the transfer of airborne dust particles to the surface through different mechanical processes, mainly Brownian diffusion, interception, inertial impaction, and sedimentation $[10,11]$. Each of these processes operates most effectively in a different particle size range.
Dry deposition is caused by impaction when an aerosol particle transported by the flow towards an obstacle cannot, when its inertia is too large, follow the flow deviation in the vicinity of the obstacle. Thus the particle collides with the obstacle surface and remains on its surface when the particle rebound is ignored.

Dry deposition also occurs via interception when particles of small inertia, which perfectly follow the streamlines of the mean flow field, pass in the vicinity of an obstacle and are held back because the distance between the particle centre and the surface is smaller than its radius [12].

The Brownian diffusion affects very fine particles, typically smaller than $0.1 \mu \mathrm{m}$. In forced convection, particles diffuse towards the obstacle surface, considered a perfect sink. The limiting deposition factor is the transfer through the boundary layer which surrounds the obstacle. In sedimentation, the deposition process is caused by gravity; it provides a direct force for moving particles through the turbulent boundary layer, through small-scale eddies near the surface and through the quasilaminar layer immediately adjacent to the surface $[13,14]$. However, gravity is an inefficient removal mechanism for particles smaller than $1 \mu \mathrm{m}$. Very large particles fall, reaching a terminal velocity. 


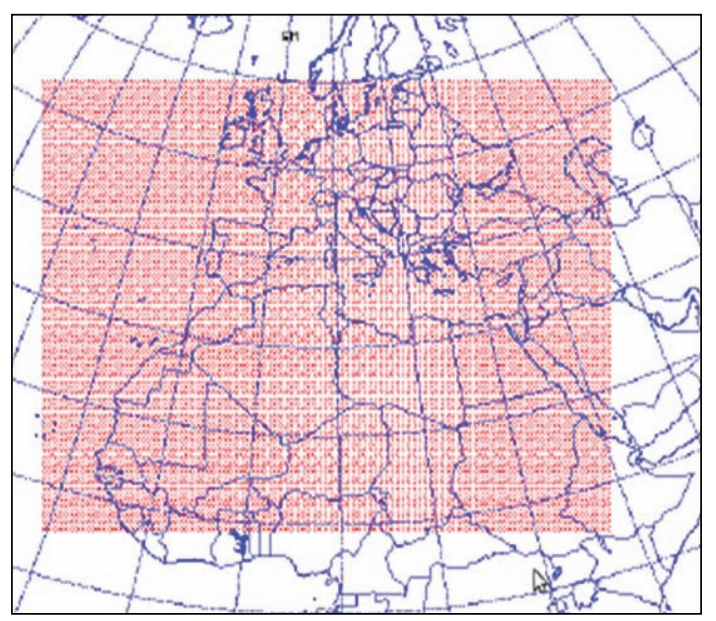

Figure 1: Area of simulation.

TABLE 1: Feature of typical dust particle.

\begin{tabular}{ccccc}
\hline$k$ & Type & $\begin{array}{c}\text { Typical particle } \\
\text { radius } R_{k}(\mu \mathrm{m})\end{array}$ & $\begin{array}{c}\text { Particle density } \\
\rho_{\kappa}\left(\mathrm{g} / \mathrm{cm}^{3}\right)\end{array}$ & Total mass $\gamma_{\kappa}$ \\
\hline 1 & Clay & 0.73 & 2.50 & 0.08 \\
2 & Small silt & 6.10 & 2.65 & 1.00 \\
3 & Large silt & 18.00 & 2.65 & 1.00 \\
4 & Sand & 38.00 & 2.65 & 0.12 \\
\hline
\end{tabular}

The dry deposition velocities are calculated as a function of particle size, density, friction velocity, and surface characteristics and they include the contributions of turbulent transfer, Brownian diffusion, impaction, interception, gravitational settling, and particle rebound $[15,16]$. Generally, the dry deposition velocity decreases with an increasing of particle size for particle smaller than $0.1 \mu \mathrm{m}$ and increases with particle size for particles larger than $2 \mu \mathrm{m}[17,18]$.

For the smallest clay and silt particles as shown in Table 1, inertial impaction, interception, and gravitational settling plays the dominant role. Deposition by impaction increases with particle size and by decreasing of wind speed, and it is also strongly influenced by surface structure $[24,25]$. Concerning the large silt and sand particles gravitational settling becomes much more important and deposition velocity increases with an increasing of particle diameter.

According to models [10], particles of around 0.1 to $0.5 \mu \mathrm{m}$ have a minimum in the deposition velocity versus particle size curve where interception is the almost only capture mechanism and for larger particles deposition increases strongly with particle size as impaction and sedimentation become significant. However, deposition of $<0.1 \mu \mathrm{m}$ particles increases with decreasing particle size as Brownian diffusion takes place.

This work focuses on the process of dry deposition during the event of 3 March 2004 over the African West coast when large quantities of dust are carried out of North Western Africa, in particular from Saharan source regions. Sahara dust storms during March 2004 have attracted much attention from the dust-research community due to their intensity, wide coverage, and endurance [26-28]. Here we aim to identify the regions of dust emission, therefore, the affected regions of dry deposition of Sahara dust after their long range transport, relatively with meteorological conditions such as wind velocity, through the extending study of Saharan dust over Island of Gran Canaria during the period of 3 March 2004.

Due to the lack of surface observations across the Sahara, a rigorous quantitative verification of the model simulations is not possible. However the simulated dust patterns are compared with data from surface weather stations in North Africa, from dry metals from stations located in Gran Canaria (Spain) and various satellite images such as (EUMETSAT) Met 8 and MODIS.

\section{Materials and Methods}

In order to investigate physical processes of dry deposition of the mineral dust over North West African coast, during an event on the 3 March 2004, the Eta system coupled with the module describing the dust cycle is applied [29-31]. The Eta model uses the primitive equations based on the hydrostatic approximation; it is formulated as a grid-point model and the partial differential equations are represented by finite difference schemes. The coarse domain is shown in Figure 1. The coarse version of Eta model has a horizontal Arakawa E grid [32], increment of $0.24^{\circ}$ resolution, while the geographical extension of the model domain is from $24.2 \mathrm{~W}$ to $51.8 \mathrm{E}$ and from 12.9 to $53.4 \mathrm{~N}$.

The dust cycle module described by a set of $k$ independent Euler type concentration equation is applied in the following form:

$$
\begin{aligned}
\left(\frac{\partial C_{k}}{\partial t}\right)= & -u \frac{\partial C_{k}}{\partial x}-v \frac{\partial C_{k}}{\partial y}-\left(w-v_{g k}\right) \frac{\partial C_{k}}{\partial z}-\nabla\left(K_{H} \nabla C_{k}\right) \\
& -\frac{\partial}{\partial z}\left(K_{z} \frac{\partial C_{k}}{\partial z}\right)+\left(\frac{\partial C_{k}}{\partial t}\right)_{\text {SOURCE }}-\left(\frac{\partial C_{k}}{\partial t}\right)_{\text {SINK }}
\end{aligned}
$$

and it takes into account the following processes: (1) dust productions applied on the basis of more sophisticated parameterization of dust mobilization process; (2) a fourparticle scheme; (3) the topography, soil, and vegetationtype data; (4) a scheme for dry deposition applied. In (1), $K$ indicates the number of particle size classes. $C_{k}$ is the dust concentration of a $k$ th particle size class, $u$ and $v$ are the horizontal velocity components, $w$ is the vertical velocity, $v_{g k}$ is the gravitational settling velocity, $\nabla$ is the horizontal nabla operator, the lateral diffusion is $(\partial C / \partial t)_{l_{\text {diff }}}=-\nabla\left(K_{H} \nabla C\right)$ and $K_{H}$ is the lateral diffusion coefficient, $K_{Z}$ is the turbulence exchange coefficient, the vertical diffusion is $(\partial C / \partial t)_{v_{\text {diff }}}=$ $-(\partial / \partial z)\left(K_{z}(\partial C / \partial z)\right)$, where $\left(\partial C_{k} / \partial t\right)_{\text {SOURCE }}$ is the source, and $\left(\partial C_{k} / \partial t\right)_{\operatorname{SINK}}$ is the sink term which includes both wet and dry deposition fractions.

The dust module include four particles $(k=4)$ categories as shown in Figure 2, resulting from the structure of desert soils based on the content of clay, small silt, large silt, and sand. For each size category $k$, typical radius $\left(R_{k}\right)$, density 


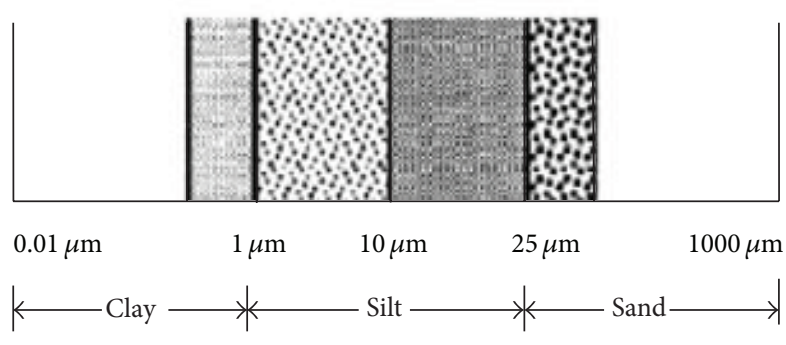

FIGURE 2: The size range of four soil particles classes [19].

$\left(\rho_{\kappa}\right)$, and the ratio between the mass available for uplift and the total mass $\left(\gamma_{\kappa}\right)$ are estimated [19], as summarized in Table 1.

The mass of the clay particles are estimated to be 1 to 2 orders of magnitude smaller than particles in range 1-10 $\mu \mathrm{m}$. Reference [19] assumes that a fraction of erodible clay is between 0.02 and 0.17 and $\gamma_{1}=0.08$.

The radius of silt particles are in the range from 1 to $25 \mu \mathrm{m}$. Small airborne particles with a diameter of $10 \mu \mathrm{m}$ or less and $25 \mu \mathrm{m}$ or less, respectively, are mainly removed through the wet and turbulent dry deposition processes. Particles larger than $10 \mu \mathrm{m}$ are basically removed by gravitational settling. In order to take into account such dependence of removal processes on particle size, silt is divided into small and large silt classes contribute with the same amount to wind erosion; that is $\gamma_{2}=\gamma_{3}=1$ (see Table 1). Having atmospheric lifetime of about 1 hour only, sand particles usually do not participate in the longer term atmospheric transport, so a value of $\gamma_{4}=$ 0.12 for the sand fraction to be available for erosion is used.

A particle dry deposition parameterization scheme [10, $33,34]$ for use in dust module is applied. This scheme includes processes of deposition by turbulent transport through the boundary layer, gravitational settling and deposition by Brownian diffusion, interception, and impaction. The scheme produces particle deposition velocities relative to the bottom transport model level expressed in terms of wind speed, temperature, and air density at the bottom model level; surface momentum drag coefficient; particle size and density; characteristics of the surface roughness elements; and several parameters derived for different surface types.

The dry deposition velocity $v_{\text {dep }}$ is defined as

$$
v_{\mathrm{dep}}=\frac{1}{\left(1 / v_{\mathrm{SL}}\right)+\left(1 / f_{\mathrm{B} 0} v_{\mathrm{IL}}\right)} ;
$$

the velocity $v_{\mathrm{SL}}$ is written as

$$
v_{\mathrm{SL}}=C_{D 10} U_{10} \frac{\sqrt{C_{D 10}}}{\sqrt{C_{D 0}}-\sqrt{C_{D 10}}} ;
$$

it represented the turbulent deposition velocity in the layer between $z_{S}$ and $10 \mathrm{~m}$, where the drag coefficients are $C_{D 10}=$ $u_{*}^{2} / U_{10}^{2}$ and $C_{D 0}=u_{*}^{2} / U_{z_{S}}^{2}$. The velocities $U_{10}$ and $U_{z_{S}}$ are specified with respect to the heights $z=10 \mathrm{~m}$ and $z_{S}$, respectively. The velocity $v_{\mathrm{IL}}$ is parameterized by

$$
v_{\mathrm{IL}}=G \sqrt{C_{D 10}} u_{*},
$$

where $v_{\mathrm{IL}}$ is the turbulent deposition velocity at the top of the viscous sublayer $z_{S}$.

The particles properties and depositing surfaces (roughness, texture, and vegetation coverage) are characterized by the function $G$ [34]. It is expressed as a sum of Brownian diffusion, interception, and impaction [10]:

$$
G=G_{\mathrm{BD}}+G_{\mathrm{int}}+G_{\mathrm{imp}},
$$

$G$ is separately considered for two kinds of surfaces: surfaces with turbulent regimes ranging from smooth to rough conditions and surfaces covered by vegetation. In (1) $f_{B 0}$ is the empirical constant which takes into account effect of the blow-off over the vegetation surfaces.

\section{Results and Discussion}

The most outstanding feature during the initial stages of this episode was the intensification of a high pressure system over the subtropical Atlantic Ocean accompanied by a cyclogenesis over central north Sahara.

On 3 March 2004 at 06 UTC, wind at 10 meters high struck the western regions of North Africa such as west Sahara, Northern Mali and Mauritania, and southwest Algeria. After that, it took an anticlockwise direction and then moved in a clockwise direction above the Algerian Sahara, Mali, and Mauritania. In south Algeria and west Libya, it gained speed remarkably ranging $10-11 \mathrm{~ms}^{-1}$. However, it decreased to $6 \mathrm{~ms}^{-1}$ over the areas of south Mali. In Mauritania, the wind ranged 3-4 $\mathrm{ms}^{-1}$ at the center and 6$7 \mathrm{~ms}^{-1}$ at the south. It weakened further ranging 3-5 ms over the center of West Sahara and 4-7 ms ${ }^{-1}$ over the West African coast and near the surface of Canary Island.

At 12 UTC, wind at 10 meters high dominated all North African regions; it blew strongly over southwest Algerian Sahara, North Mali, Mauritania, and West Sahara reaching a value between 12 and $13 \mathrm{~ms}^{-1}$ over these regions. This increase in wind velocity was due to warm air masses at the center of southeast Europe, which moved in a clockwise direction reaching Northwest Africa. It continued through two ways: one headed towards southwest of North Africa and the second deviated through the Atlantic Ocean along southwest Europe.

Six hours later, It was clearly seen that near the surface the weakness wind at 10 meters high covered approximately the West parts of North Africa including the regions of southwest Algeria and Northern Mali, Mauritania,and West Sahara; it reached 6 to $7 \mathrm{~ms}^{-1}$; therefore these meteorological controls (the diminishing of wind velocity) establish the dust content of the atmosphere, hence its transpire dust deposition over these regions. The dust clouds from West Africa Figure 13(a) extend far into the atmosphere [35-37], reaching up to $5 \mathrm{~km}$ or higher in the midtroposphere. Much of this dust is advected out by the upper-level winds and due to its strength and stability, it exports dust to Island of Gran Canaria.

The island's proximity to the West Saharan Desert results in the common presence of Saharan winds, $30 \%$ of the year, for a 5-year period [38], which carry abundant aeolian dust. 


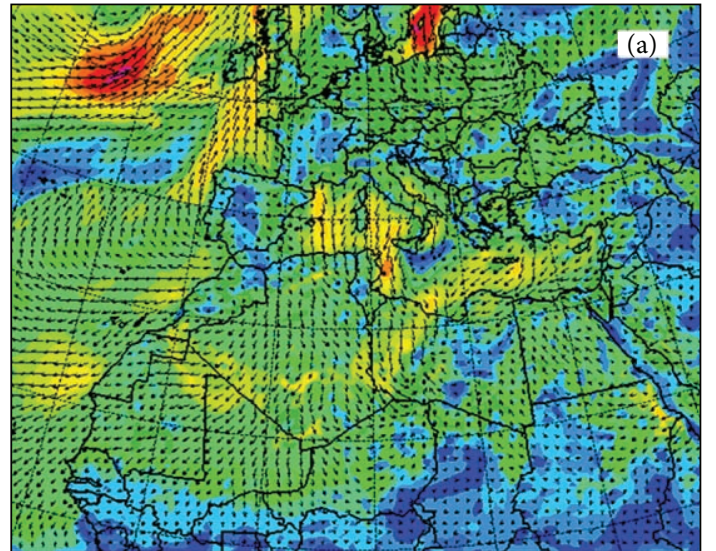

$\begin{array}{llllllllllllllllllll}0 & 1 & 2 & 3 & 4 & 5 & 6 & 7 & 8 & 9 & 10 & 11 & 12 & 13 & 14 & 15 & 16 & 17 & 23\end{array}$

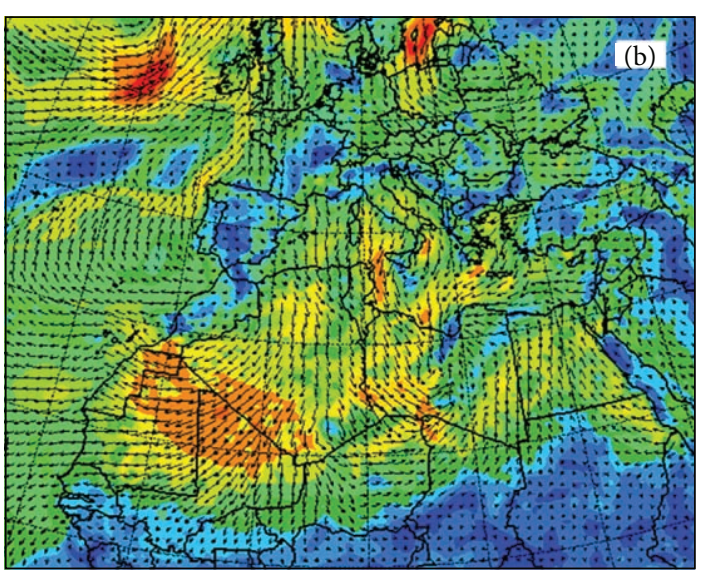

$\begin{array}{lllllllllllllllllll}0 & 1 & 2 & 3 & 4 & 5 & 6 & 7 & 8 & 9 & 10 & 11 & 12 & 13 & 14 & 15 & 16 & 17 & 23\end{array}$

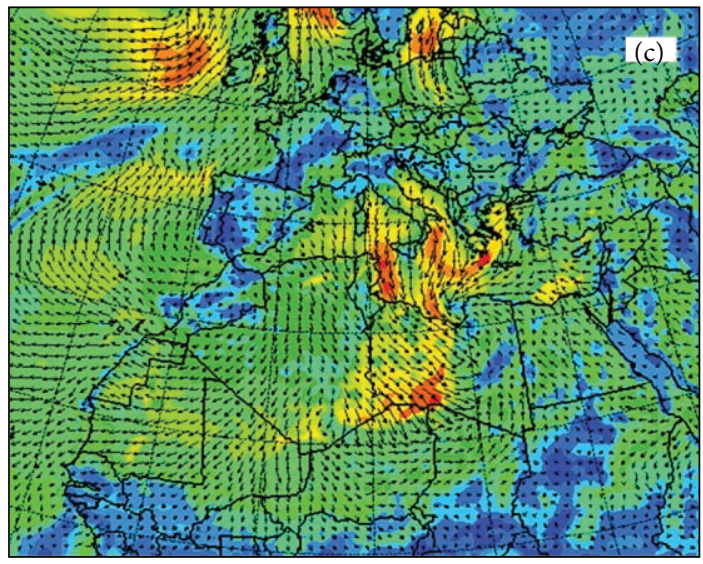

$\begin{array}{lllllllllllllllllllll}0 & 1 & 2 & 3 & 4 & 5 & 6 & 7 & 8 & 9 & 10 & 11 & 12 & 13 & 14 & 15 & 16 & 17 & 23\end{array}$

FIgURE 3: Wind at 10 meters high on 3 March 2004 at (a) 06 UTC, (b) 12 UTC, and (c) 18 UTC.

The rest of the year is dominated by trade winds, from an NNE direction [39]. Air mass trajectories and the composition of particles also point to West Africa as a source of dust outbreaks in the Canary Islands.

According to these synoptic conditions, mineral dust transported produces frequent dry hazes over West Africa and West Africa coast on 3 March 2004 at 18 UTC. The dynamics of the synoptic conditions were described by [14, $26,40]$ and are not repeated here. Figure 3 illustrates the evolution of patterns wind at 10 meters high through this dry deposition episode.

Total dry deposition at 06 UTC in Figure 4(a) shows obviously the deposition over the most North Africa and over the Atlantic water. A level amount of dry deposition of the total particles is available in Algerian Southwest; this is caused by meteorological conditions in those areas, Figure 3(a).

Dry deposition of clay particles seem over the regions of Libya, Algeria Sahara, Mali, and Mauritania, also over West Sahara; it ended over the Atlantic Ocean; the greater value was distinct at south Algeria, Figure 4(b). This deposition amount is governed by the physical process of dry deposition linked with wind at 10 meters high. As is now well established that the clay particle usually transported over long distances, but it settles over the area mentioned above; this is due to the decreasing of wind velocity; when it increases the fine particles can travel long distances from their sources. In addition the fine particle supported also the suspensions in short term depending on the wind falling when moved above the surfaces. Depending on the aerodynamic deposition, the small silt particle set down with a maximum value over south Algeria a border with Sahara of Mauritania, Figure 4(c).

The coarse large silt and sand particles, respectively, have a high settling velocity from the air and therefore it is not carried more than few hundred kilometers away by winds, as shown in Figures 4(d) and 4(e); however coarser particles will drop out of suspension first where the role of sandy particles in generation of dust particles by saltation processes is crucial.

At 12 UTC, total dry deposition expand more than the earlier time above West Africa, in the Sahara regions of south Algeria, Mali, and Mauritania, also south Morocco and West Sahara. The highest quantity evident ended in Mauritania Sahara is observed in Figure 5(a); the increasing amount of total dry deposition is greatly depending on the Weathering history in the source region for uptake dust from 


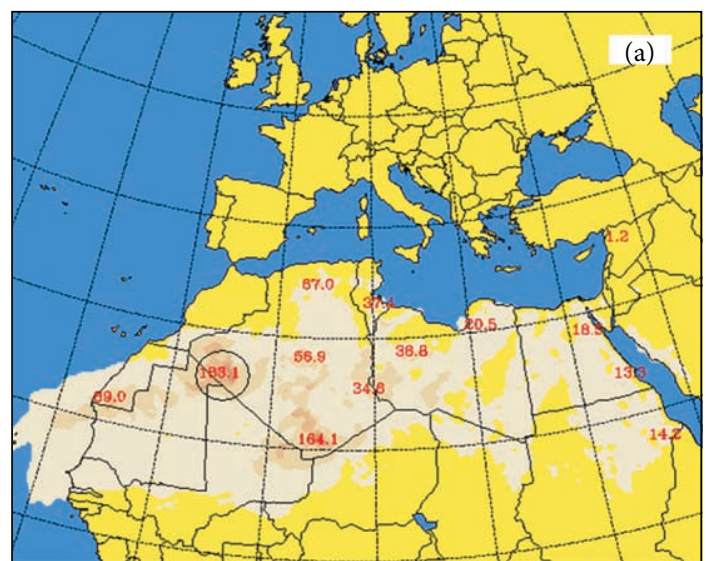

$1 \quad 11 \quad 31 \quad 611011512112813614515516617819111051$

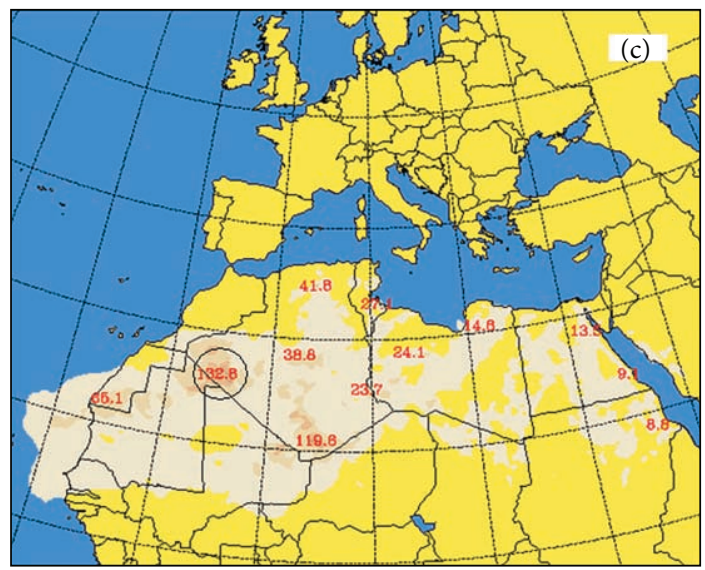

$1 \quad 11 \quad 31 \quad 61 \quad 1011512112813614515516617819111051$

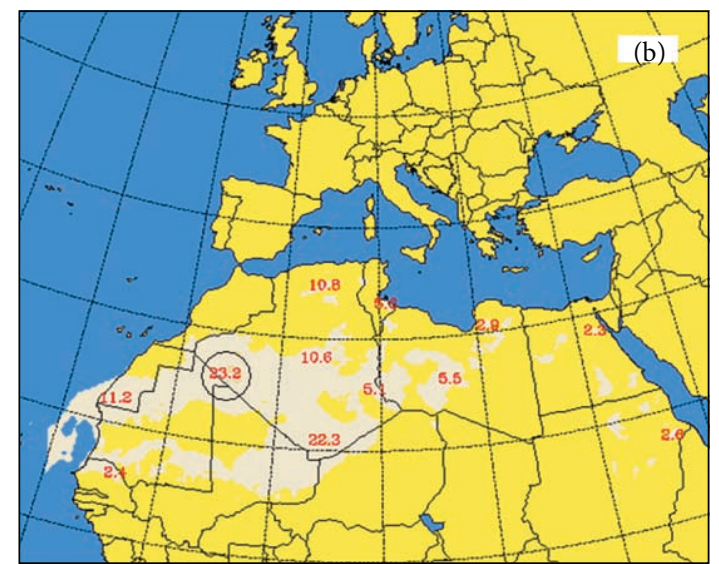

$1 \quad 11 \quad 31 \quad 61 \quad 1011512112813614515516617819111051$

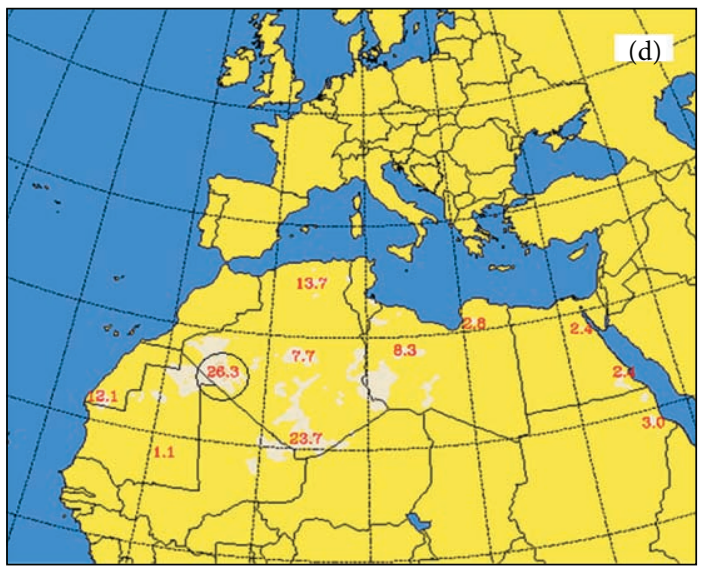

$1 \quad 11 \quad 31 \quad 61 \quad 1011512112813614515516617819111051$

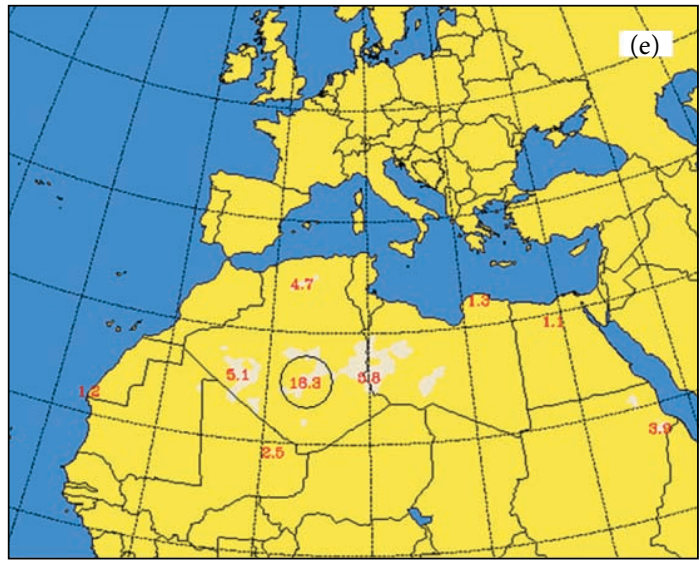

$1 \quad 11 \quad 31 \quad 61 \quad 1011512112813614515516617819111051$

FIGURE 4: Dry deposition on 3 March 2004 at 06 UTC, (a) total dry deposition, (b) clay particle, (c) small silt particle, (d) large silt particle, and (e) sand particle. The black circle indicates the maxima of dry deposition. 

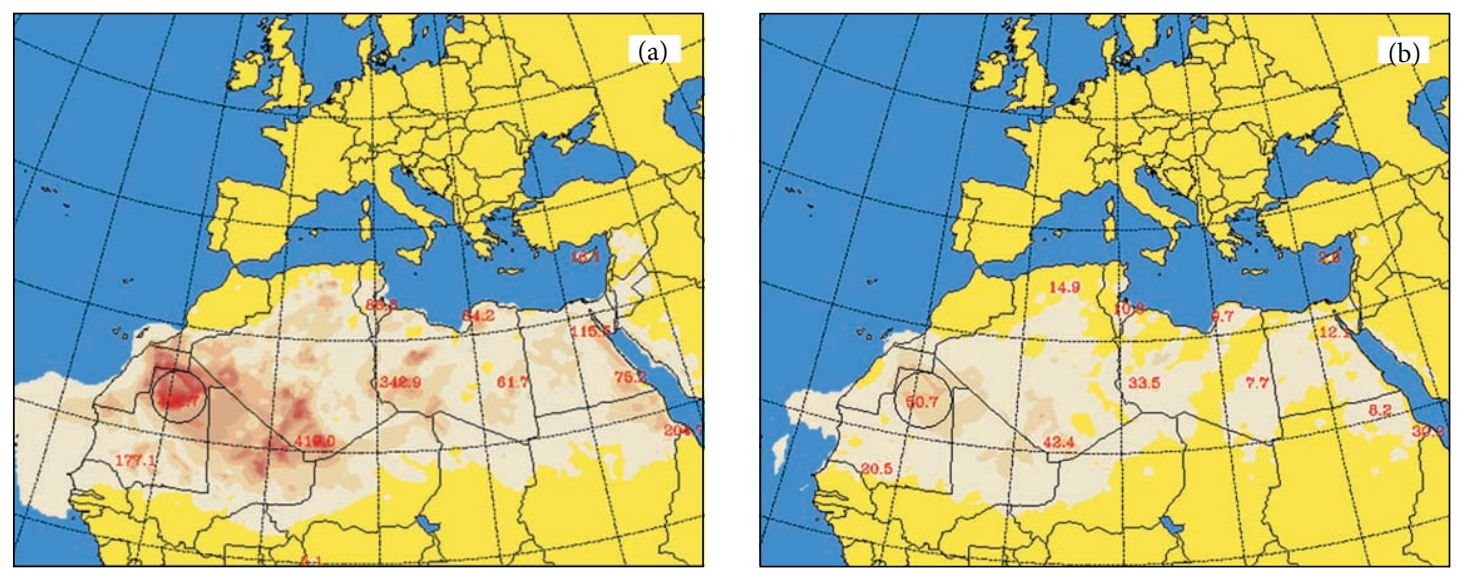

$1 \quad 1131 \quad 611011512112813614515516617819111051$
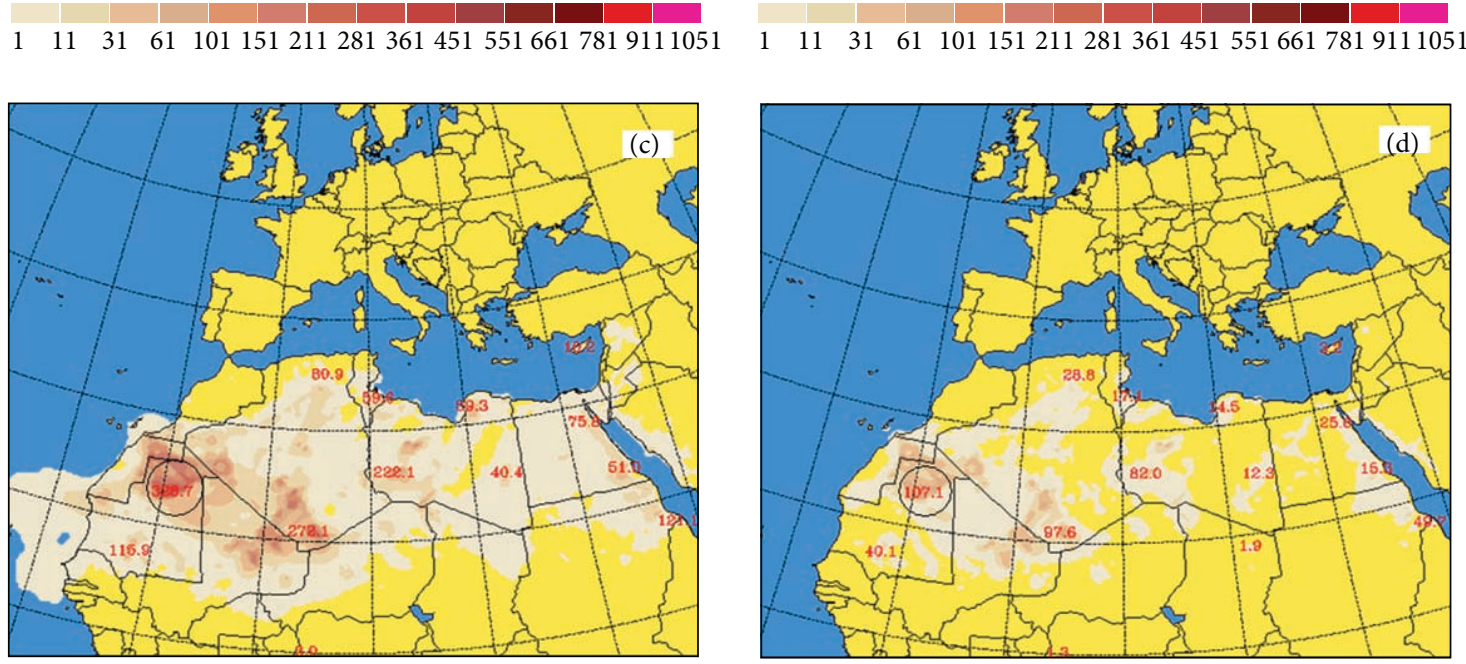

$1 \quad 1131 \quad 611011512112813614515516617819111051 \quad 1 \quad 11 \quad 31 \quad 611011512112813614515516617819111051$
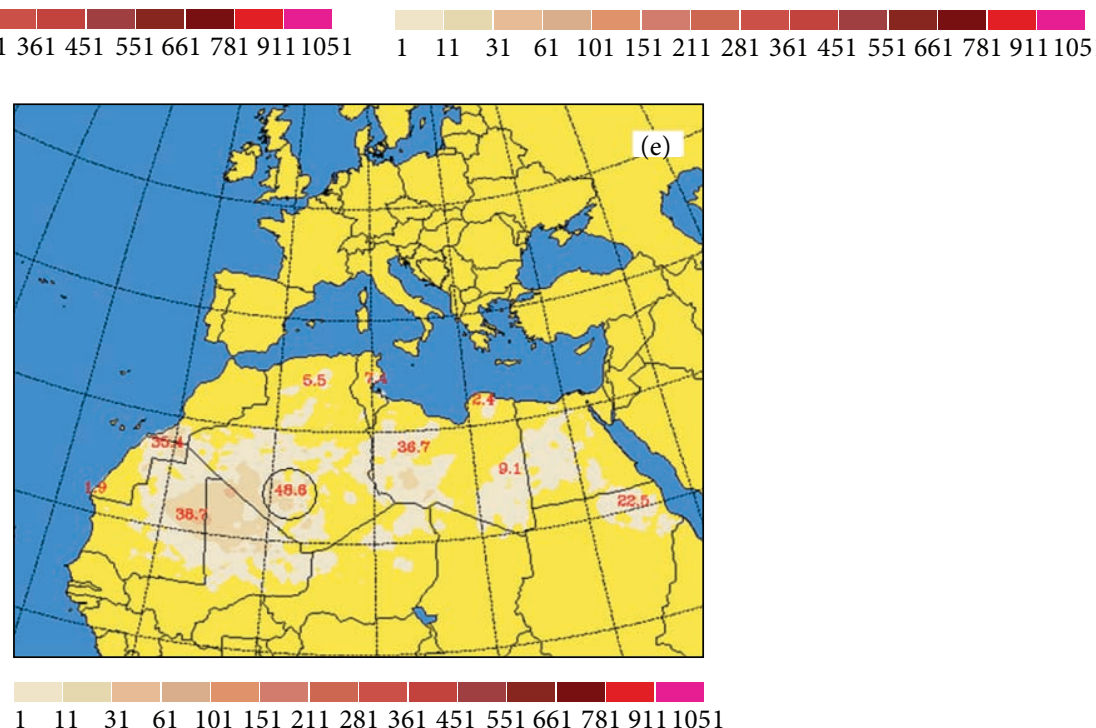

Figure 5: Dry deposition on 3 March 2004 at 12 UTC, (a) total dry deposition, (b) clay particle, (c) small silt particle, (d) large silt particle, and (e) sand particle. 
the atmosphere. Dust did not sediment in dry mechanism only in West Africa Sahara but it comprised the West Africa coast, Canary Island,and Atlantic water.

Figure 5(b) shows the dry deposition of clay particle over the Sahara sources, like Sahara of Mauritania where it registered the maximum value; the clay particles were also entrained in long range transport; when it passed by the Atlantic water, it was captured by water droplets due to water evaporations (at 12 UTC); it became heavier than the original mass; therefore it was removed from the atmosphere and it sited at the Atlantic water controlled by wind velocity, Figure 3(b).

At this time the small silt particles have level amount in deposition than the other particles as shown in Figures 5(a) and 5(c); the greater quantity has been registered over Mauritania Sahara, due to the relationship between their masses and wind velocity controlling factor and because the clay masses are less than the small silt, the clay particles can be lifted quickly and transported before their settling, it was either deposited around the areas of dust production or put down above the Atlantic water and Canary Island after relinquish the sources, Figures 3(b) and 5(c).

Regarding the large silt and sand particles, there are no height accumulations of dry deposition over Atlantic water and Canary Island, for the reason that the coarse masses of these particles as illustrated in Figures 5(d) and 5(e), outlawed to be lifted rapidly than the other sizes.

It can be concluded that the small silt particle has greatest amount in dry deposition than the other particles on 3 March 2004 at 12 UTC. The meteorological conditions favors to uptake particle from the atmosphere and depending on the physical and chemical properties of their sizes during the same period, the large silt and sand set down closed to the source of dust production.

Total deposition for the period of 3 March 2004 at 18 UTC indicated the increase of dustiness in the regions of south Algeria, Sahara of Mali and also the regions of North Mauritania and West Sahara; the deposition also exposed over the Atlantic Ocean and Canary Island, Figure 6(a).

In Figure 6(b), the clay particle registered a maximum value over Northern Mauritania, according to its size; it fleet far from the areas dust sources production; it entrained in different mechanical processes generating the dry deposition such aerodynamic deposition (impaction by inertial force and interception), in function with weather condition dominated by Saharan winds, Figure 3(c).

Figure 6(c) depicts the dry deposition of small silt particles in the areas of south Algeria and Sahara of Mali, and the regions of North Mauritania and West Sahara; the deposition amounts in this time are elevated comparing to the deposition quantity of clay particles; this due to the diameter of the small silt particles and because the clay particles can travel greater distances and have longer atmospheric residence times [41]. The small silt particles have also an important value of dry deposition over Gran Canaria because of the mechanical deposition privileged by the synoptic conditions on $3 \mathrm{March}$ 2004 at 18 UTC to extending dust of West Africa over the Canary Islands $[42,43]$.
At 18 UTC, as shown in Figure 6(d), large particles (large silt and sand) are deposited over North Africa areas where the maximum value marked in south Algeria, Northern Mali and Mauritania, and West Sahara and Sahara of Libya.

For large silt and sand particles, gravitational settling becomes much more important and deposition velocity increases with increasing particle diameter, large particles fall, reaching a terminal velocity.

Removal processes of atmospheric mineral particles by dry deposition occurs at the surface in the vicinity of the dust source areas, and because larger particles cannot participate in long range transport, the deposition of clay and small silt particles are commonly investigated in Island of Grand Canaria from 1 to 3 March 2004.

In the model, in a layer close to the surface of 10 meters depth, known as the surface layer, the dry deposition dominates; this layer consists in two virtual layers usually considered to calculate dry deposition velocities $[10,15,33$, 44, 45]: in the first layer close to the surface, dust dry deposition fluxes are controlled by turbulent diffusion and Brownian diffusion, interception and impaction (for small particles), or gravitational settling (for large particles); in the second layer over viscous layer, called the constant flux layer [33], used to be limited to turbulent processes and gravitational settling [19].

The dry deposition velocity $v_{\mathrm{dp}}$ is dependent on height from 10 meters to the surface composed of the gravitational settling velocity and a modification related both to the dry deposition velocity due to turbulent motion in the upper layer and the dry deposition velocity due to molecular diffusion in the lower layer. Figure 7 illustrates the dependence of $V_{\mathrm{dp}}$ of both particles small silt and clay versus the dates as computed by the model. Two noticeable features can be observed: deposition velocity is strongly dependent on particle size and varies from $10^{-4}$ to $0.1 \mathrm{~cm} \cdot \mathrm{s}^{-1}$.

Firstly, for small silt particles having diameters of $12.2 \mu \mathrm{m}$, the highest deposition velocities rise steadily from 2 , at 18 UTC, to 3, at 18 UTC, March 2004, where it achieves a maximum value $\left(0.1 \mathrm{~cm} \cdot \mathrm{s}^{-1}\right)$ due to gravitation and especially to impaction and interception processes at the surface; for this size the deposition velocity increases with particle diameter as gravitational settling becomes more significant.

Secondly, for particle sizes at $1.46 \mu \mathrm{m}$, having the smallest dry deposition velocities against small silt particles, $v_{\mathrm{dp}}$ of clay particles increased for the same period where $v_{\mathrm{dp}}$ of small silt increased too; for even smaller particles, the deposition velocity increases due to the increased efficiency of molecular. Dry deposition velocity of clay particles is controlled by the turbulent processes (size independent); for these sizes, dry deposition does not appear to be an efficient removal process, and this could lead to longer atmospheric residence times.

Dry deposition velocity does not only depend on particle properties, but also on atmospheric conditions and surface characteristics $[10,11,15,16]$. This is evidence for the variations of dry deposition velocities of both particles (small silt and clay) from day to day until it accomplishes the highest values at 18 UTC on 3 March 2004. Our study revealed that 


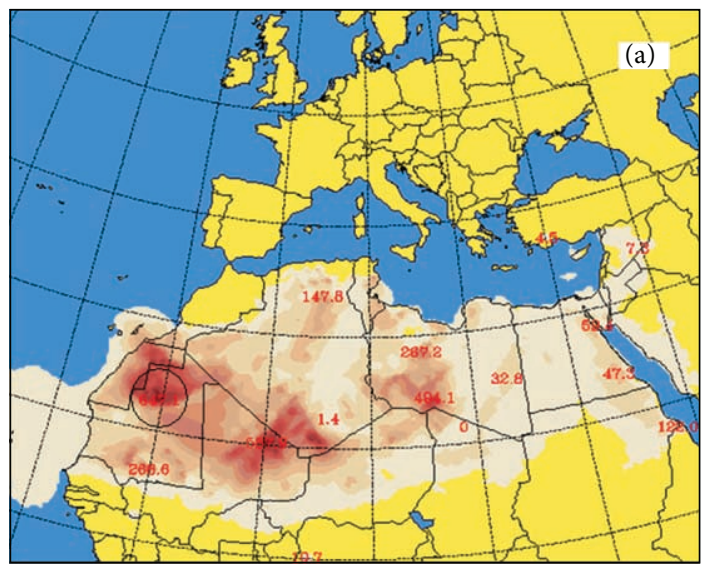

$1 \quad 11 \quad 31 \quad 61 \quad 1011512112813614515516617819111051$

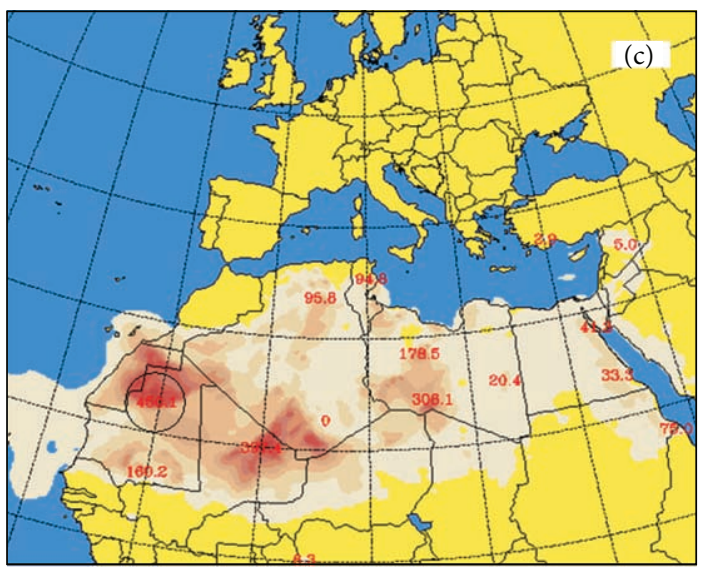

$1 \quad 1131 \quad 61 \quad 1011512112813614515516617819111051$

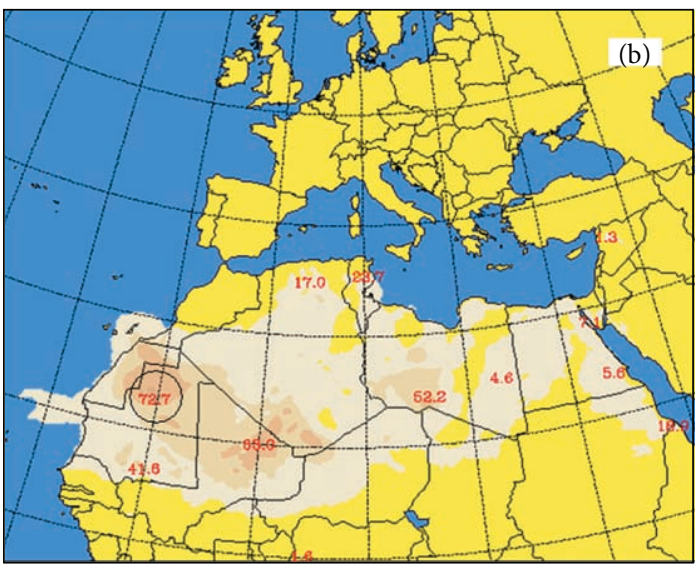

$1 \quad 11 \quad 31 \quad 61 \quad 1011512112813614515516617819111051$

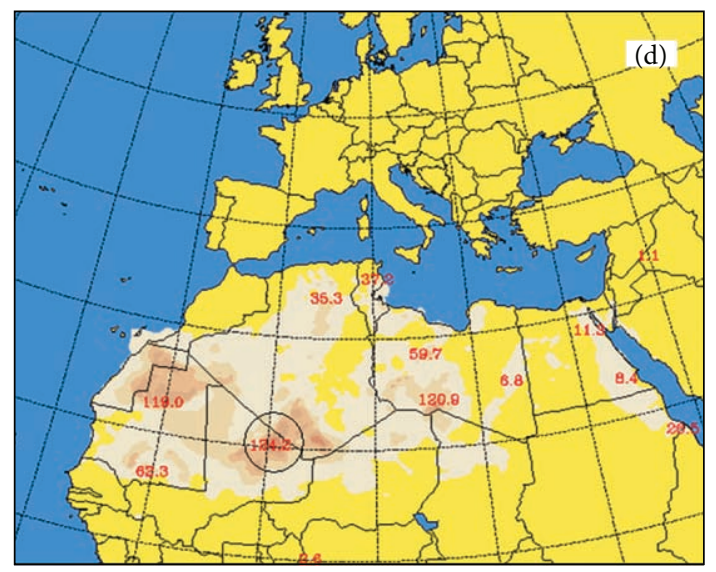

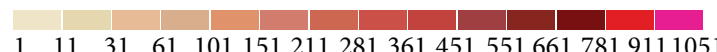

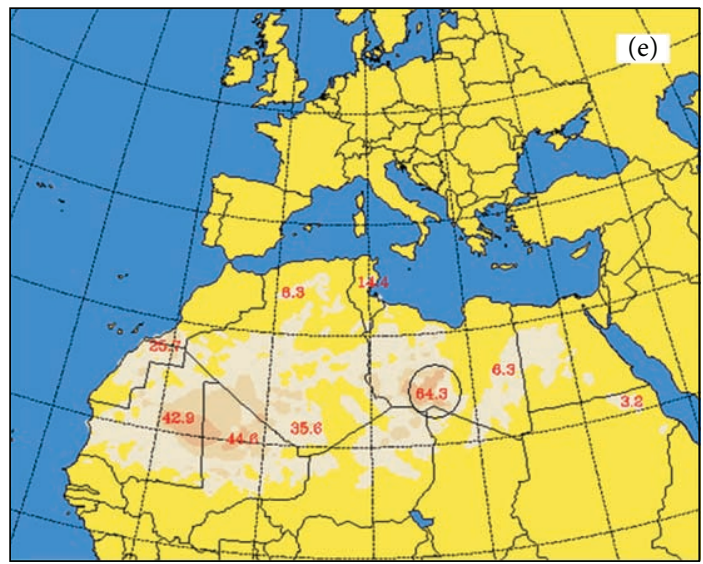

$1 \quad 11 \quad 31 \quad 61 \quad 1011512112813614515516617819111051$

FIGURE 6: Dry deposition on 3 March 2004 at 18 UTC, (a) total dry deposition, (b) clay particle, (c) small silt particle, (d) large silt particle, and (e) sand particle. 


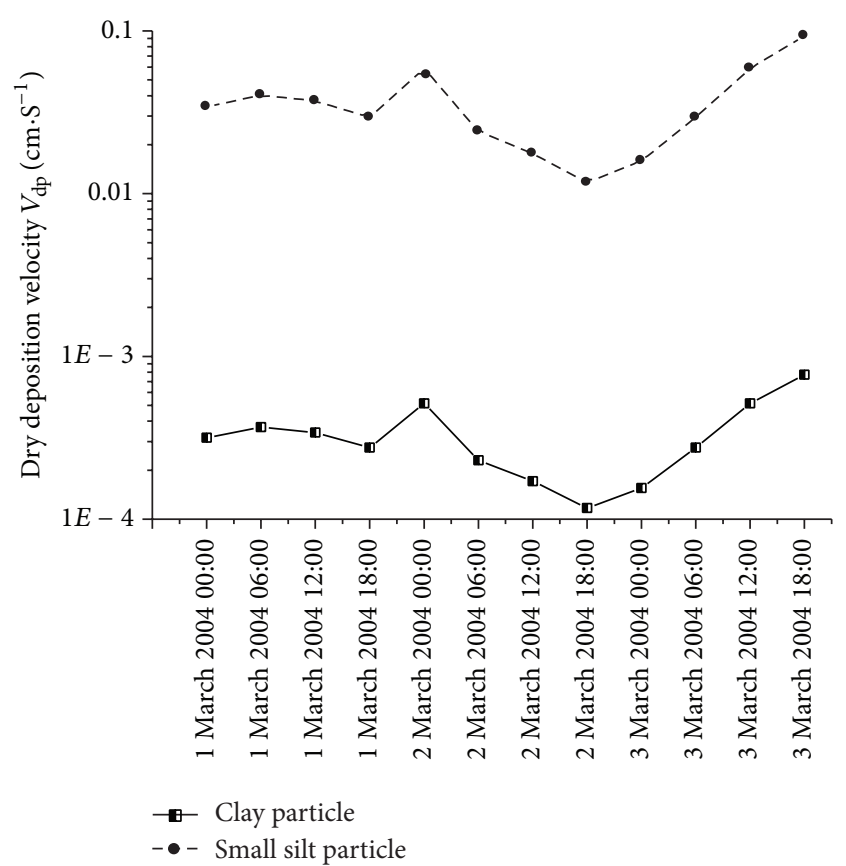

FigURE 7: Evolution of dry deposition velocity of both particles clay and small silt over Gran Canaria from 1 to 3 March 2004.

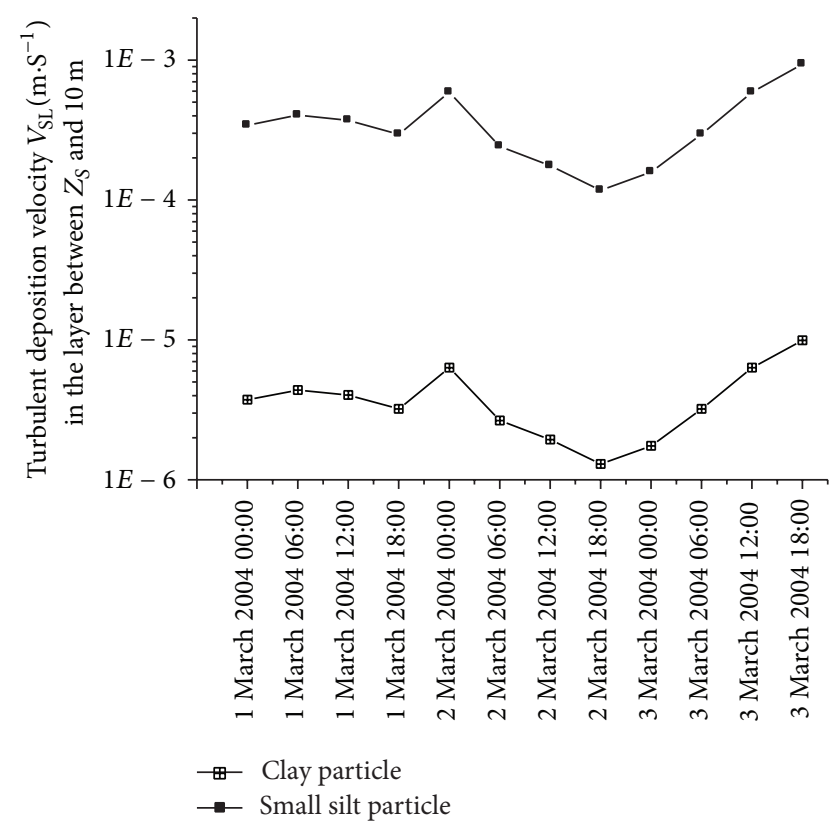

Figure 8: Evolution of turbulent deposition velocity of both clay and small silt particles between the layer $z_{s}$ and 10 meters above the Island of Gran Canaria from 1 to 3 March 2004.

particle deposition velocity is very sensitive to meteorological conditions, as well as particles sizes.

Depending on the mechanisms for the generation of turbulence $[46,47]$, the atmosphere boundary layer (surface layer) and atmospheric quantities (e.g., wind speed, temperature, and aerosol concentration) vary rapidly with height, and turbulence is predominantly generated by wind shear and

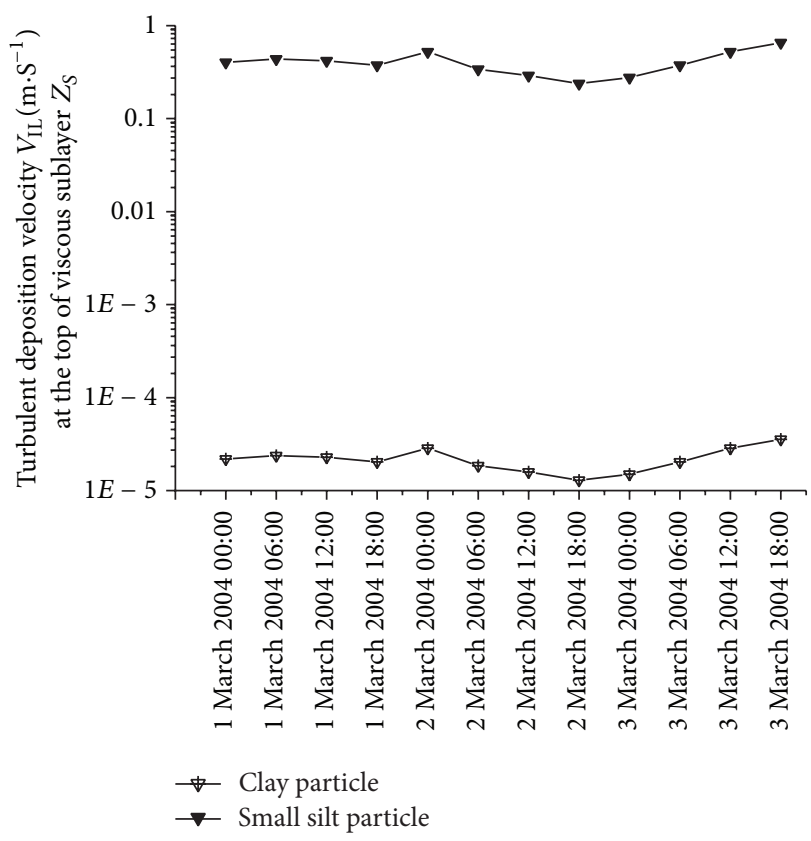

FIgURE 9: Evolution of turbulent deposition velocity at the top of viscous sublayer $z_{s}$ above the Island of Gran Canaria from 1 to 3 March 2004.

the buoyancy effects are secondary although they may still be significant. However the buoyancy effect is not treated here.

The dry deposition event is treated in the surface layer because the entrainment of soil particles is determined by the momentum transfer from this layer to the surface and the motion of sand particles confined to this layer [45]. The surface layer below a certain height (say about $10 \mathrm{~m}$ ) is divided into two sublayers: turbulent deposition velocity $v_{\mathrm{SL}}$ in the layer between $z_{s}$ and $10 \mathrm{~m}$ and turbulent deposition velocity $v_{\mathrm{IL}}$ at the top of viscous sublayer $z_{s}$; in the upper layer, dry deposition results from settling and turbulent diffusion (Figure 8), while in the lower layer, it results from settling and molecular diffusion (Figure 9). The surface is usually rough, because it consists of various elements such as plants, rocks, and buildings [47]. A criterion for determining whether the surface is smooth or rough is the Reynolds number, whereas it is used in the calculation for both rough and smooth surfaces.

In the model calculation, the surfaces with turbulent regimes ranging from smooth to rough conditions include sea, bare soil and ice surface are considered; however the dry deposition over the surface covered by vegetation according to scheme of [34] is not taken into account here.

In the two-layer dry deposition model, in the upper layer, turbulent diffusion dominates over molecular diffusion, and in lower layer the molecular diffusion dominates over turbulent diffusion $[45,48,49]$.

In Figure 9, at the top of viscous layer at high $z_{s}$, say a few millimetres, very close to the smooth surface (i.e., the roughness elements are sufficiently small), turbulence is generally very weak due to the very strong effect of viscous dissipation. In this case, the transfer processes are dominated 


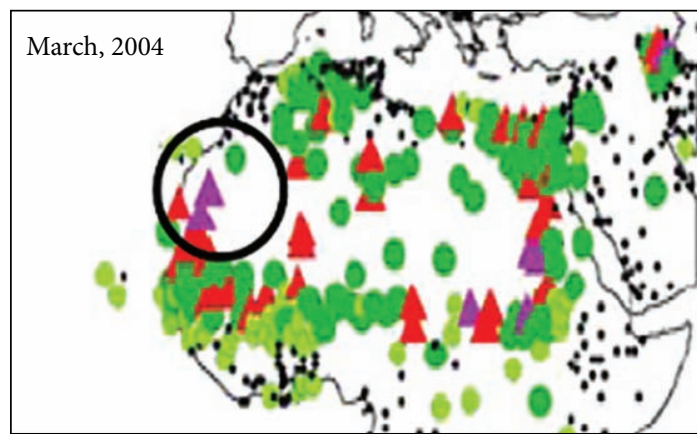

- No dust event

Blowing dust

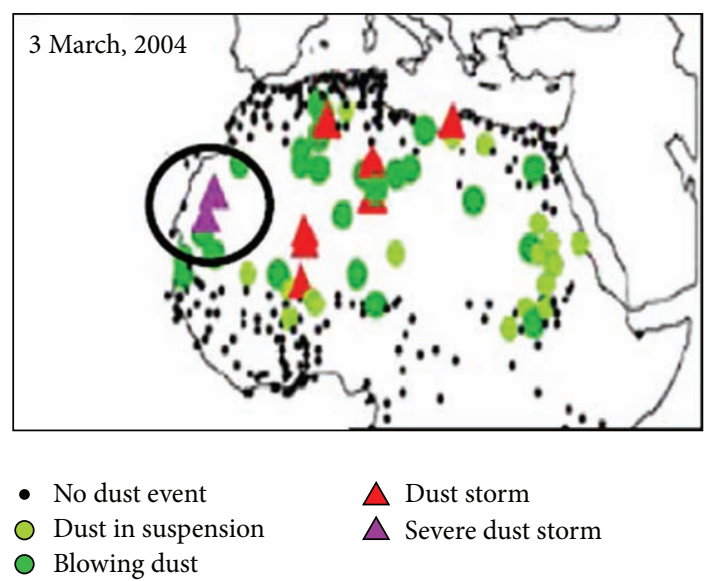

(b)

Figure 10: Distribution of the surface weather stations in North Africa (black dots) and daily dust weather records for the period 3 March 2004 (a). The dust weather records for the entire month of March 2004 are shown in (b), (shaded) and the dust weather records (symbols) for 3 March 2004 [20].

by the inertial impaction, more efficient for particles with $12.2 \mu \mathrm{m}$ in diameters and gravitational settling.

Thus the dry deposition velocity is a function of both turbulent velocities $v_{\mathrm{SL}}$ and $v_{\mathrm{IL}}[50,51]$; the highest dry deposition velocities tend to increase from 2, at $18 \mathrm{UTC}$, to 3, at 18 UTC, March 2004 together for clay and small silt particles.

It appears for all velocities from Figures 7, 8, and 9 that the clay and small silt particles have the same convergence; this is due to the meteorological setting that changes from time to time as shown in Figure 4 and the surface deposition as well as flow properties. This statement establishes that the physical mechanisms responsible for dust dry deposition are not only depending on the properties of the dust particles.

The simulation results are validated as far as observational data would permit. The data available for the comparison are the following.

The distributions of the surface weather stations in North Africa and the dust records for March 2004 are shown in Figure 10(a). The stations in the northern and southern parts of North Africa are relatively dense but quite sparse in the interior Sahara. Dust weather is recorded by human observers on the basis of visibility and can be grouped into the categories of "dust in suspension," "blowing dust," "dust storm," and "severe dust storm" using the coding regulations of significant weather defined by World Meteorological Organization. The dust weather reports suggest that in March 2004, the entire Sahara-Sahel region to the north of about $10^{\circ} \mathrm{N}$ was affected by dust activity.

Dust storms and severe dust storms which are shown in Figure 10(b) were observed in Algeria, Mauritania, Libya, Egypt, Sudan, and so forth. To the south of the Mediterranean (Algeria, Libya, and Egypt), widespread "dust in suspension" and "blowing dust" were observed. To illustrate the evolution of the dust activities during the period of 3 March 2004, the daily dust weather records are shown in Figure 10. Despite the sparse distribution of the weather stations, it is seen that dust storms and severe dust storms occurred on 3 March 2004.

The results of dust dry deposition pattern and evolution are compared with the dust weather records in Figure 10. The results in Figures 4, 5, and 6 correctly clarify the development of the dust deposition on 3 March 2004 and the simulated evolution of the dust pattern was consistent with observations.

The results revealed that on 3 March 2004 dust storms and their deposition developed in northwestern Sahara in conjunction with the cyclogenesis and the formation of the cold front. Much of the dust emitted from Western Sahara was trapped in the cold air mass, forming a marked dust frontal structure [20] and as a result total dry deposition in Figures 4(a), 5(a), and 6(a) revealed this marked dust frontal excessively. The dust front then advanced towards the Atlantic Ocean where it deposited over Canary Island, maintaining its shape for several times to follow.

The Instituto de Astrofísica de Canarias (IAC) has been set up to provide detailed informations and statistics about meteorological of the Observatorio del Teide (OT) on Island Tenerife.

Data from meteorological stations, namely, Observatorio del Teide (OT), Island of Tenerife (2.390 $\mathrm{m}$ a.s. $16^{\circ} 30^{\prime} 35^{\prime \prime}$ West, $28^{\circ} 18^{\prime} 00^{\prime \prime}$ North), were used. From 1 to 3 March 2004 statistical scores of wind velocity were derived and compared for both the observation and the model simulation. Note that the wind data from the meteorological station are only available at height of $10 \mathrm{~m}$ above the ground.

From data in Figure 11, it can be seen that most of the wind speed forecast exhibit a good correlation between the model wind velocity simulation and validation with (OT) station data mainly on 3 March 2004. The clarity of decreasing wind velocity for both the observation and the model simulation from the episode of 3 March 2004 (06 UTC-18 UTC) caused the dry deposition process over Gran Canaria. 


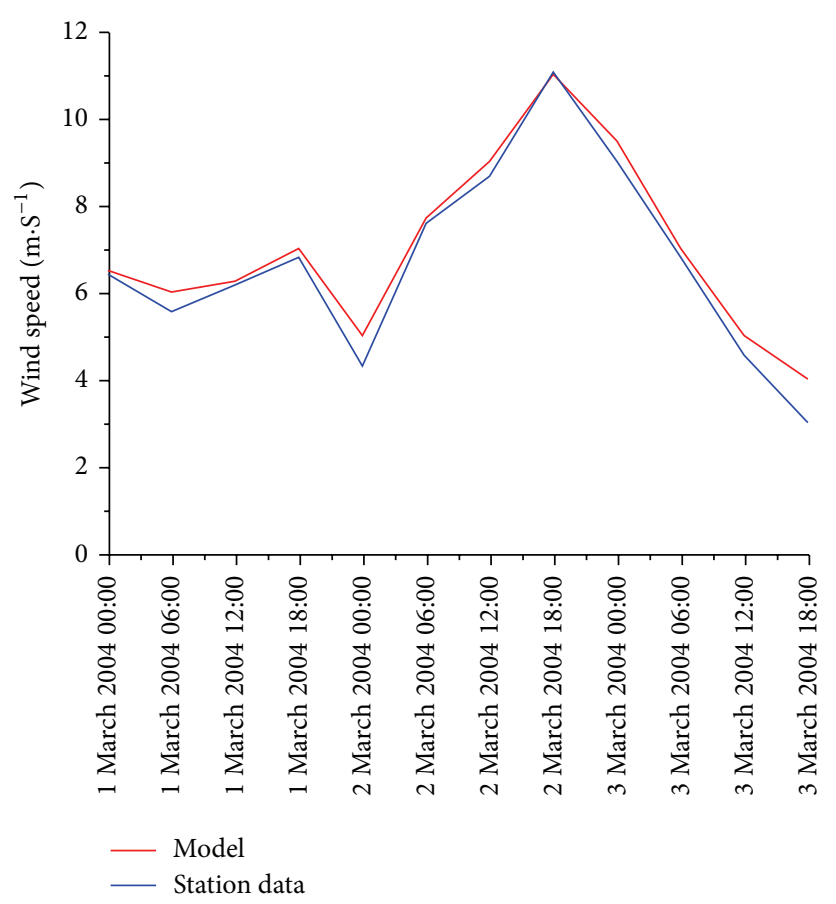

FIGURE 11: Comparison of wind speed at 10 meters high of (OT) station with the model results from 1 to 3 March 2004. The observational (blue graph) and simulated wind speed data (red graph) showed a good correlation score of decreasing wind velocity on 3 March 2004.

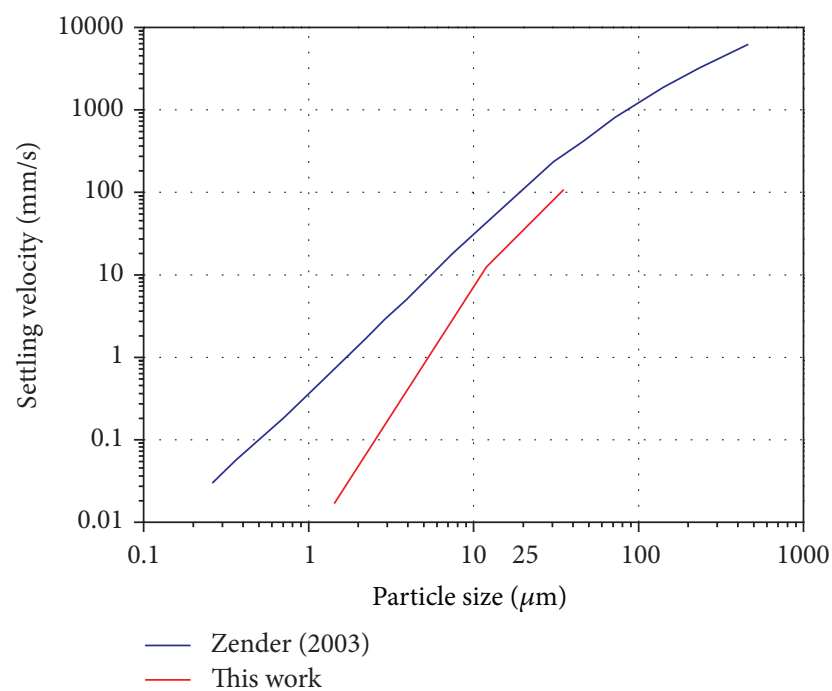

FIGURE 12: Settling velocity as a function of particle sizes.

According to Table 1, clay particles have a diameter of $1.46 \mu \mathrm{m}$ and silt particle ranging into small silt and large silt particles have diameters ranging $12.2-36 \mu \mathrm{m}$; sand particles have a diameter of $76 \mu \mathrm{m}$. Relating these sizes to the real world, clay particles have diameters less than $2 \mu \mathrm{m}$, silt particles range from 2 to $50 \mu \mathrm{m}$, and sand size particles are greater than $75 \mu \mathrm{m}$. In the work of [17], concerning settling velocity as a function of particle size, particles larger than $20 \mu \mathrm{m}$ in diameter fall disproportionately faster: $50 \mu \mathrm{m}$ particles fall at about $500 \mathrm{~mm} / \mathrm{s}$ or half a meter per second. Particles smaller than $20 \mu \mathrm{m}$ settle very slowly. $10 \mu \mathrm{m}$ particles fall at only $30 \mathrm{~mm} / \mathrm{s}$; smaller particles fall even more slowly: $2 \mu \mathrm{m}$ particles fall at only $1 \mathrm{~mm} / \mathrm{s}$. Particles capable of traveling great distances usually have diameters less than $20 \mu \mathrm{m}$.

On the graph of [17], these particles fall at a speed of about $100 \mathrm{~mm} / \mathrm{s}$. Therefore by comparisons of terminal velocity as a function of particle sizes between the work of [17] and the present work, it is found from Figure 12 that [17] started by a finest particle equal to $0.5 \mu \mathrm{m}$ in diameter; however the finest particle used in this work is clay $1.46 \mu \mathrm{m}$ in diameter which settles so slowly; it falls at $1 \mathrm{~mm} / \mathrm{s}$, concerning the other particles (small silt, large silt, and sand); the settling velocity values reveal a good correlation with those diameters as well as those used in [17].

According to the European Organization for the Exploitation of Meteorological Satellites (EUMETSAT) Met-8 and Moderate Resolution Imaging Spectroradiometer (MODIS) images for 3 March 2004, a cold air outbreak from Europe to Western Africa caused a major dust storm over large parts of West Africa. The dust was blown out across the Atlantic Ocean and out over Canary Islands as shown in Figure 10. When the wind reduced, Figure 11, the results can be compared qualitatively with the EUMETSAT images detecting dust load above West Africa areas of dust production as well as above the Canary Island areas of uptake dust from the atmosphere, as shown in Figures 13 and 14. At 12 UTC, dense dust clouds over North Africa at around $15^{\circ} \mathrm{N}$ and a dust front over the Atlantic in the coast of West Africa can be clearly seen. A comparison of Figure 5(a) and Figure 13(a) confirms that the results identify the key features of dust deposition event. At 12 UTC, Figure 13(a), a somewhat more diffused dust pattern over the northern African continent and an elongated dust front over the Atlantic water were clearly 


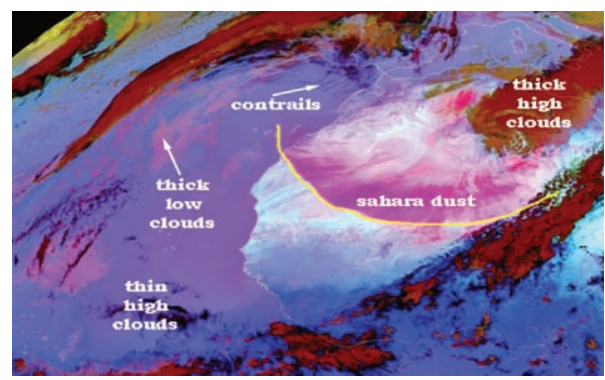

(a)

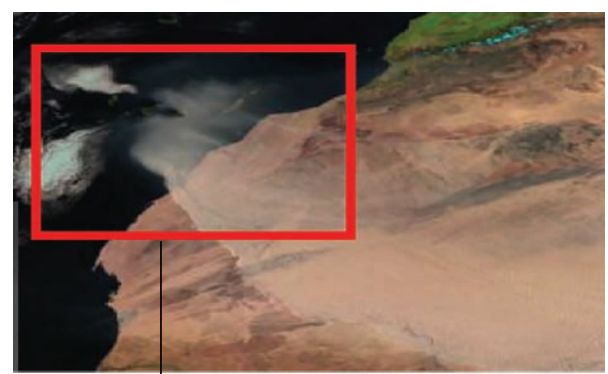

(b)

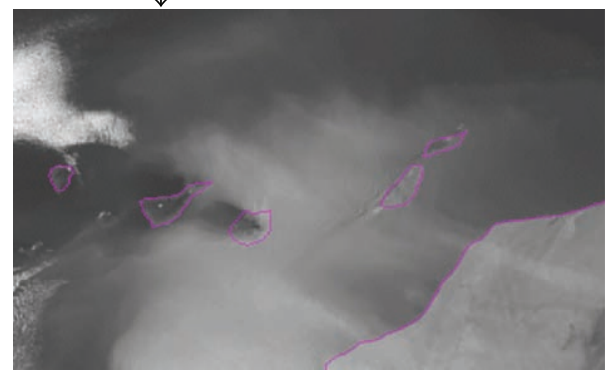

(c)

Figure 13: (a) Dust clouds from West Africa extending to Atlantic Ocean and Canary Islands, detected by (EUMETSAT) Met- 8 on 3 March 2004 at 12 UTC. (b) Dust storms from the Northwest Africa and high dust concentrations above Canary Island at 18 UTC where dry deposition occurred. The reddish rectangle indicates the occurring zone of dry deposition. (c) The Zoom image above the Canary Island showing high dust concentration originating from North West Africa regions. (a), (b), and (c) are taken from Visible Earth (2004).

visible. Dust transported from the Sahara was widespread across the regions of south Algeria, Mauritania, and west Sahara, and at 18 UTC, dust font reached thousands of kilometers over Atlantic water as revealed by Figure 6 .

At 18 UTC, a thickest dry deposition over Mali and Mauritania, a border of West Sahara, as depicts in Figures 6(a) and 14(b) indicating that was a strong dust emission in those regions.

A comparison of Figures 14(a) and 14(b) confirms that the results reflected the important features of dry deposition over the regions mentioned above.

The dry deposition during the event of 3 March 2004 can be qualitatively compared with the MODIS (on board NASA's Aqua) images, as shown in Figure 14. The MODIS images show that dust in suspension remained widespread

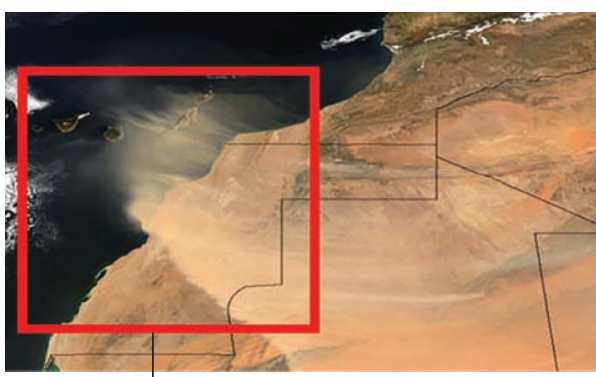

(a)

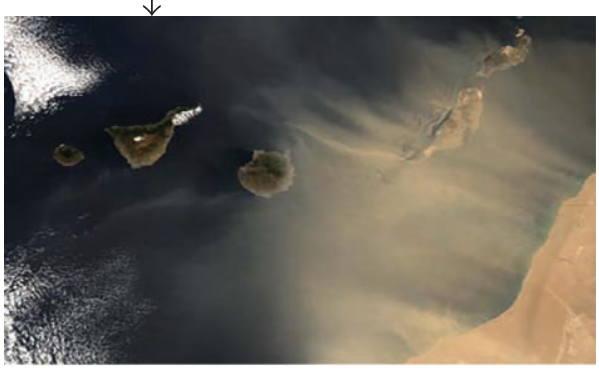

(b)

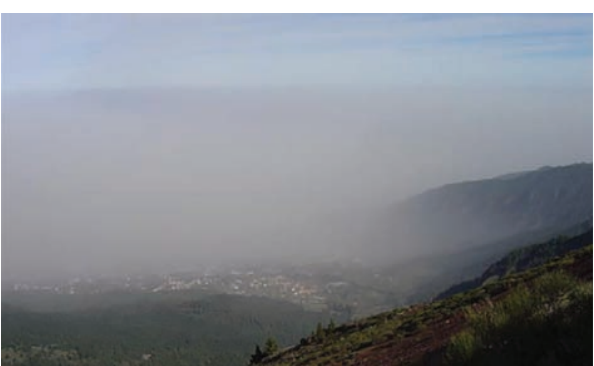

(c)

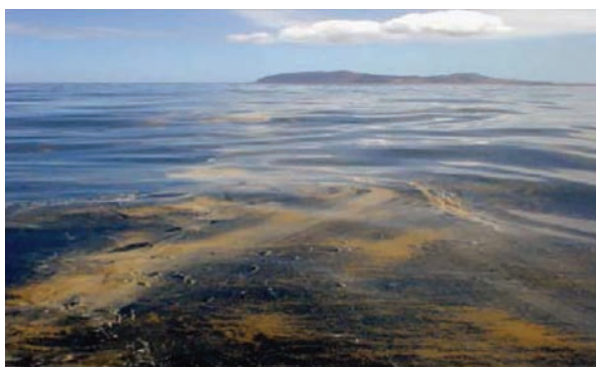

(d)

FIGURE 14: Moderate Resolution Imaging Spectroradiometer detected Saharan dust storm of Northwest Africa above Canary Islands. (a) MODIS image with $2000 \mathrm{~m}$ resolution and (b) MODIS image with $250 \mathrm{~m}$ resolution. Images were taken from Visible Earth (2004). (c) Desert dust of West Africa out over Canary Island during 3 March 2004, photo: "Eugenio Rodriguez 03 March (2004)" and (d) dust over coast Gran Canaria, may be associated with Saharan dust storm of North Western Africa [21].

and evident on 3 March 2004 over the entire West Africa. On the 3 March, strong dust emission was visible in the Northwestern part of Africa and a thick plume of dust covered the northern parts of Mali, Mauritania, and West Sahara, extending to the tropical Atlantic. From Figures 4, 5, and 6, it is evident that the results correctly show the development of 
TABLE 2: Mean concentration of $\mathrm{Al}$ included in mineral Sahara dust according to [54].

\begin{tabular}{ccc}
\hline & Mean concentration & \\
Saharan dust & Saharan soils & $\begin{array}{c}\text { Saharan dust end } \\
\text { member }\end{array}$ \\
\hline $\mathrm{Al}, \% \quad 7.09 \pm 0.79(11 \%)$ & $5.78 \pm 1.68(29 \%)$ & $7.09 \pm 0.79(11 \%)$ \\
\hline
\end{tabular}

dry deposition over the Atlantic Ocean and Canary Island; this is manageable after a strong dust storm covered the areas of North West Africa. These features observed from the MODIS satellite images were well reproduced by the results. The images included in this work from EUMETSAT can be found at http://oiswww.eumetsat.org/.

African dust transport constitutes a large fraction of the annual atmospheric deposition in the Canary Islands. The analyses of aerosol samples and deposition measurements over Gran Canaria during different dust deposition episodes have been carried out during 3 March 2004 [22, 23].

Dust sampling was carried out at three sample stations located in Gran Canaria: Pico de la Gorra (1930 m a.s.l., $\left.27^{\circ} 56^{\prime} \mathrm{N}, 15^{\circ} 33^{\prime} \mathrm{W}\right)$, Tafira $\left(269 \mathrm{~m}\right.$ a.s.l, $\left.28^{\circ} 06^{\prime} \mathrm{N}, 15^{\circ} 24^{\prime} \mathrm{W}\right)$, and Taliarte (close to sea level; $27^{\circ} 59.5^{\prime} \mathrm{N}, 15^{\circ} 22^{\prime} \mathrm{W}$ ) as seen in Figure 15. The most important African dust events were chemically characterised; hence the dry metal deposition fluxes of $\mathrm{Al}, \mathrm{Fe}, \mathrm{Co}$, and $\mathrm{Mn}$ [23] have been estimated as shown in Figure 16. A dust outbreak was observed with maximum dust concentrations throughout 3 March 2004. The maximum deposition fluxes were observed during this period when large quantities of dust are carried out of North Western Africa, in particular from Saharan source regions.

The uplifted dust has a lower grain size that the parent material is enriched in the clay fraction, which produces a mineralogical and then chemical fractionation $[3,52]$. Consequently, a better reference for mineral sources of aerosol would be the mean composition of soils or silt sediments, which are the result of soil erosion, as described by [53].

Guieu et al. [54] reported the concentration of aluminum that characterized the Saharan dust, $\mathrm{Al}$ included dust at about $\mathrm{Al}(\%)=7.09 \pm 0.79$ in Sahara dust, and Sahara dust end member as shown in Table 2.

In Figure 17, the aluminum values are converted to equivalent mineral dust concentrations based on the average concentration of $\mathrm{Al}$ in Figure 16(a) and are compared with model simulation of the period of 3 March 2004. During the Saharan event, the composition of the particles that deposited over Gran Canaria reflects the average composition of the eroded areas that affects the Saharan desert [55-57].

The greatest differences between the mean and max concentrations of Al were observed in 3 March 2004. The Al concentration was increased by mineral dust transport with cyclones originating from North Africa [56] through 3 March 2004 at 18 UTC. Highest concentrations of particles were observed at Gran Canaria on 3 March 2004 as demonstrated in Figures 13 and 14; the relatively great values at Gran Canaria are due to the fact that major dust events from Northwest Africa Sahara are often observed in this region [57].
TABLE 3: Comparison between textural analyses of Aeolian dust sample collected in Gran Canaria and model output related to fraction of dry deposition of four grain sizes.

\begin{tabular}{lc}
\hline Kubilay et al. [58] & Present work \\
\hline Clay $(<2 \mu \mathrm{m})$ & Clay $(1,46 \mu \mathrm{m})$ \\
m. silt $(8-16 \mu \mathrm{m})$ & Small silt $(12,2 \mu \mathrm{m})$ \\
c.-v.c. silt $(16-62 \mu \mathrm{m})$ & Large silt $(36 \mu \mathrm{m})$ \\
v.f. sand $(62-125 \mu \mathrm{m})$ & Sand $(76 \mu \mathrm{m})$ \\
\hline
\end{tabular}

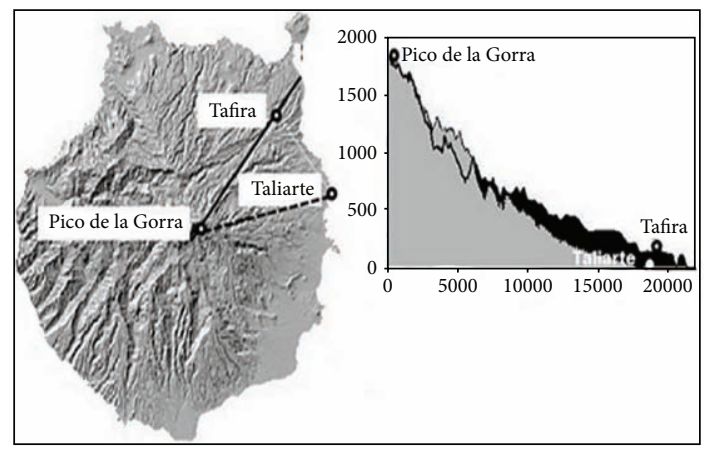

FIGURE 15: Location of the three sampling sites in Gran Canaria: Pico de la Gorra (1930 m a.s.l., $\left.27^{\circ} 56^{\prime} \mathrm{N}, 15^{\circ} 33^{\prime} \mathrm{W}\right)$, Tafira $(269 \mathrm{~m}$ a.s.l, $28^{\circ} 06^{\prime} \mathrm{N}, 15^{\circ} 24^{\prime} \mathrm{W}$ ), and Taliarte (close to sea level; $27^{\circ} 59.5^{\prime} \mathrm{N}$, $\left.15^{\circ} 22^{\prime} \mathrm{W}\right)$ [22].

The aluminum concentration in Gran Canaria appears to be a useful tracer and used as indicator for the intrusion of dust from surrounding desert of Northwest Africa areas, which are primary sources of mineral aerosol. According to Figure 17 a good correlation was found between the model simulation of mineral dust concentration and concentrations of $\mathrm{Al}$ data measured in the station located in Gran Canaria.

As a result of the large Northwest gradient in the dust concentration in Gran Canaria, small shifts in the large scale wind systems or in the dust sources in Africa could result in very large changes in dust transport and in the related deposition to the areas of Canary Island. This applies to the day-to-day changes in dust concentrations (which are subject to the winds associated with the controlling large-scale meteorological situation) and also to longer term concentrations (which are related to climatologically factors and the associated long-term changes in meteorology).

According to [59], components of collected aeolian dust samples in Island of Gran Canaria were mostly in the coarse silt grain fraction ( $46 \pm 12 \%)$ with low clay size percentages $(8 \pm 9 \%)$. Grain size distribution curves were found to be Polymodal with maxima corresponding to clays $(1.5-2 \mu \mathrm{m})$, very fine-fine silt $(6-8 \mu \mathrm{m})$, coarse silt $(22-35 \mu \mathrm{m})$, and very fine sands modes $(62-130 \mu \mathrm{m})$, as shown in Figure 18.

There were an increase in the very fine-fine and coarse silt fraction and a decrease of the coarse silt fraction, in agreement with conditions of suspension transport prior to accumulation. However, the particles chosen in this episode of dry deposition in Island of Gran Canaria are corresponding to those used in [59], as clarified in Table 3. 


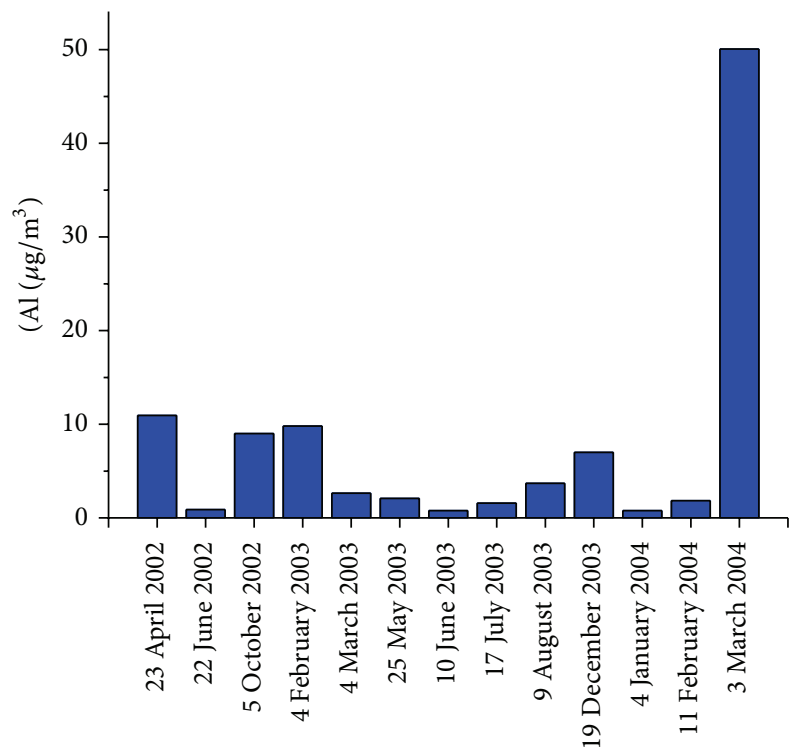

(a)

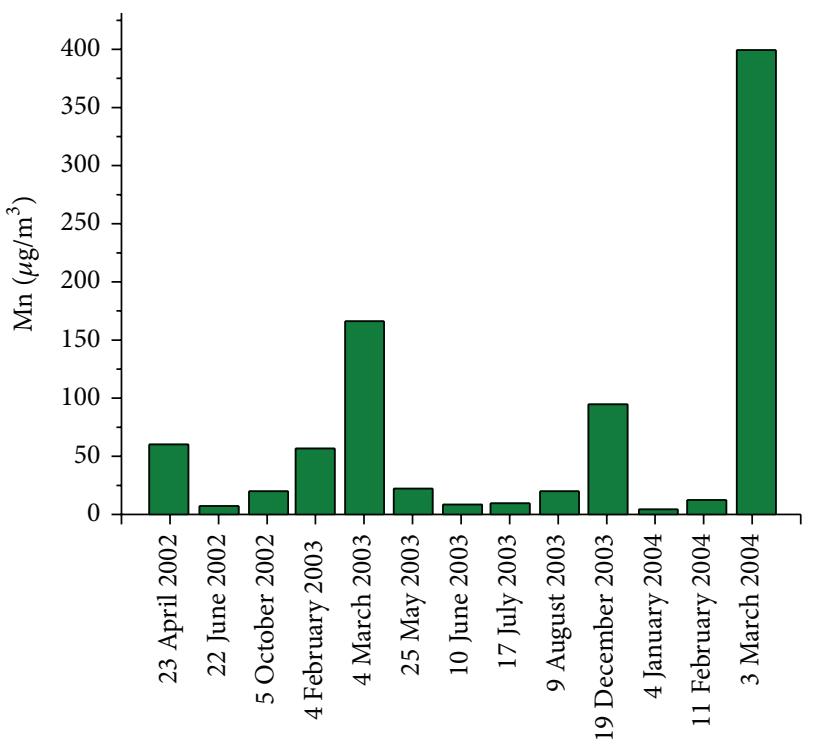

(c)

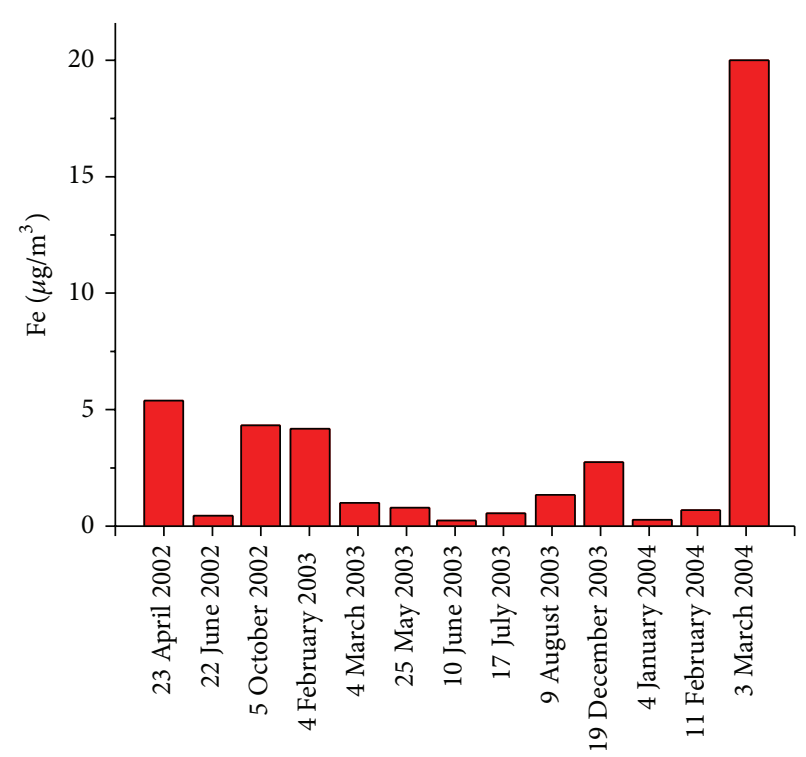

(b)

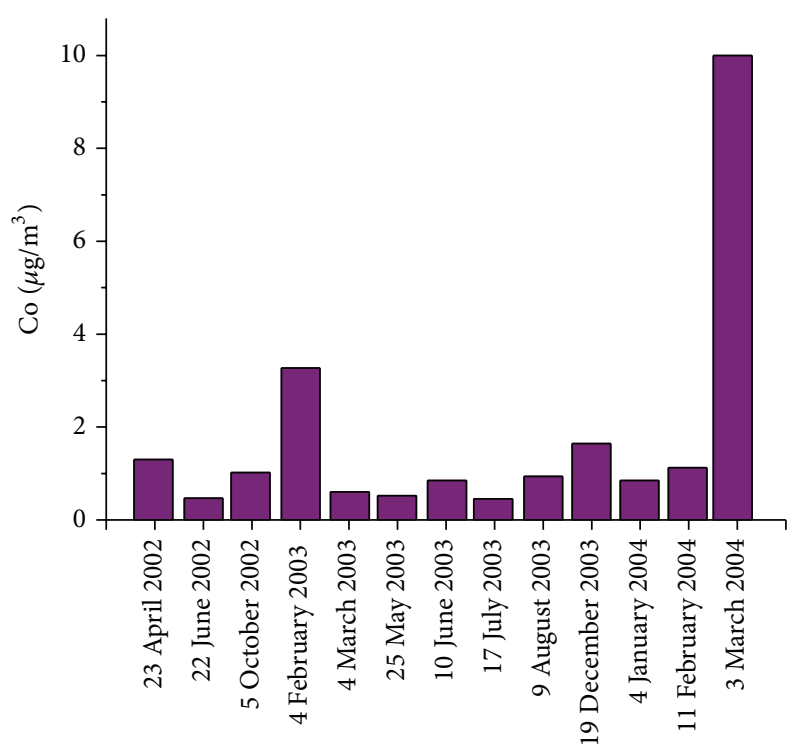

(d)

Figure 16: Dry metal deposition fluxes of (a) Al, (b) Fe, (c) Mn, and (d) Co at Gran Canaria, high dry deposition marked on 3 March 2004 [23].

The model output related to fraction of dry deposition particles originating from airborne Saharan dust of Northwest Africa (Figure 6) in the Island of Gran Canaria on 3 March 2004 at 18 UTC is shown in Figure 18; a significant remark is the high values of small silt particles (60\%) approximately twice fraction of m.silt particle collected in Gran Canaria, owing to the high dry deposition in this period. As it was described before the sand particle cannot transported a long distances on account of it size (see Table 1), therefore it was not set up over Gran Canaria in this deposition event. The negative fraction of large silt signifies that these particles do not show their deposition in this time exactly, unless it achieves a value of $10 \%$, when it is a subjected to wind speed transport associated with particle diameter. This causes temporal changes in dust deposition.

The clay particles from the model show high deposition similar to the same particles collected in Gran Canaria, the decreasing of the percentage amount of this particle signifies that this particle can travel a long distances due to its small size and due to meteorological conditions favorable before it entrained in the deposition process in the Island of Gran Canaria. Due to high dry deposition of clay particles at 18 UTC, the small fraction of this particle shown by the model $(30 \%)$ is equal to the maximum clay particles collected In Gran Canaria. It was concluded from these comparisons between the model results and the textural analyses of aeolian 


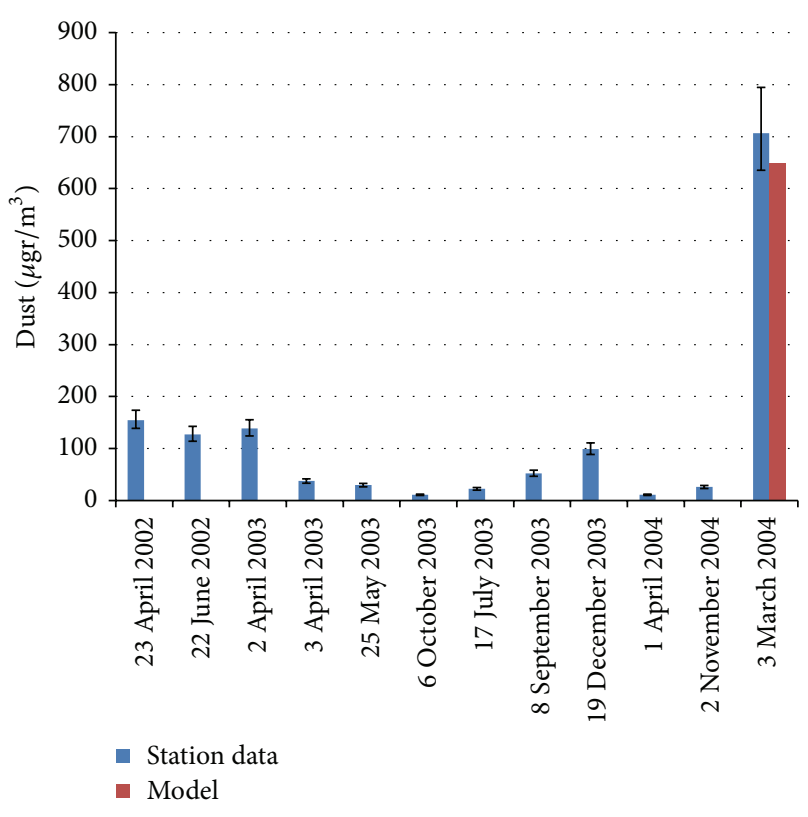

Figure 17: Concentration of $\mathrm{Al}$ in different dust episodes from Gran Canaria Stations converted to mineral dust concentration and compared with model simulation of dust deposition event of 3 March 2004.

dust samples on 3 March 2004 at 18 UTC that a very important quantity of dry deposition from Northwest Africa Sahara was recorded. The dry deposition of the four particles over Gran Canaria follow to many factors such as particles diameter and the meteorological conditions associated with the aeolian dust.

\section{Conclusions}

The major sources for long-range transport of mineral dust in North-eastern subtropical Atlantic are located in arid regions of Northwest Africa. A long front of Saharan dust sweeps across south Algeria, Mali, Mauritania, and Western Sahara and produces frequent dry haze over the vicinity of the source areas; hence the deposition of clay and small silt particles is commonly investigated.

Throughout the event studied here, the dry deposition amount is governed by the physical process of dry deposition concurrent with wind at 10 meters above the ground; consequently most of the wind speeds tend to support evidence of an excellent link between the model wind velocity and (OT) station data.

The uplifted dust has lower grain sizes of the parent material including small silt and clay is a better reference of aerosol compositions for the eroded areas; hence the $\mathrm{Al}$ concentration taking place in the area of Gran Canaria was increased on 3 March 2004 when large quantities of dust were carried out of North Western Africa. A good correlation was found between the model simulation of mineral dust concentration and concentrations of Al data measured. The aluminum concentration in Gran Canaria appears to be a

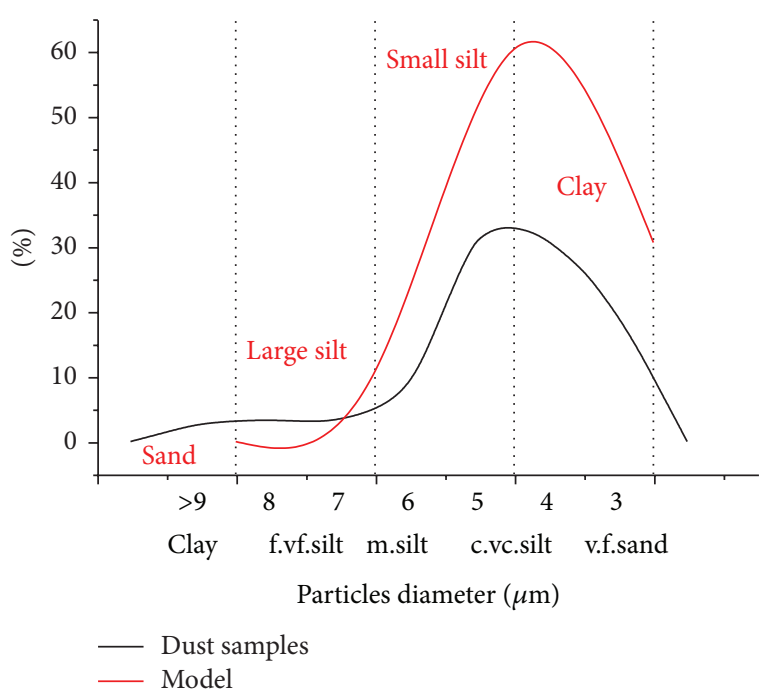

FIGURE 18: Comparison between the polymodal textures fraction form the Aeolian dust samples in the Island of Gran Canaria and the model results of dry deposition fraction on 3 March 2004 at 18 UTC.

useful tracer and is used as an indicator for the intrusion of dust from the surrounding desert areas of Northwest Africa.

Grain size distribution curves were found to be Polymodal in the comparison between textural analyses of aeolian dust samples collected in Gran Canaria and model outputs related to the fraction of dry deposition of four particles including clay, small silt, large silt, and sand. At 18 UTC there was a significant quantity of dry deposition amount of both small silt and clay particles. However large particles fall, reaching a terminal velocity, and are not carried more than few hundred kilometers away.

Even though dry deposition velocity is depending not only on particle properties, but also on atmospheric conditions and surface characteristics, for small silt particles the deposition velocities rise steadily due to gravity and especially impaction and interception processes at the surface and by decreasing wind speeds; for particles of this size the deposition velocity increases with particle diameter as gravitational settling becomes more important, whereas clay particles are controlled by the turbulent processes (size independent); at the top of viscous layer, very close to the smooth surface, turbulence is generally very weak due to the very strong effect of viscous dissipation. For these sizes dry deposition does not appear to be an efficient removal processes, and this could lead to longer atmospheric residence times. For large silt and sand particles gravitational settling becomes much more important and deposition velocities increase with increasing particle diameter.

Dry deposition provides a significant mechanism for the removal of the four particles from the atmosphere, following many factors such as particle diameter and meteorological conditions associated with the aeolian dust and by a reason of the synoptic condition frequent occurrence of falling wind at 10 meters high, the dust deposition of both particles clay 
and small silt over the West Africa coast become extensive at 18 UTC on 3 March 2004.

As a result, the atmosphere over Western Africa is almost permanently dry with significant amount of mineral dust deposited during the event of 3 March 2004, from that the dust production is enhanced during this period because of the breaking of soil crusts, in this respect if the ground is drier more dust will rise and arrive to Gran Canaria. It is reasonable to assume that the factors affecting the Gran Canaria dust dry deposition record depend on particle size structure and by the occurrence of proper synoptic conditions.

\section{Conflict of Interests}

The authors declare that there is no conflict of interests regarding the publication of this paper.

\section{Acknowledgments}

The authors thank the group of Atmospheric Modeling and Weather Forecasting of the University of Athens. A special acknowledgment is to the University of de Las Palmas de Gran Canaria (Spain), the Instituto de Astrofisica de Canarias (IAC), the European Organization for the Exploitation of Meteorological Satellites (EUMETSAT), and Moderate Resolution Imaging Spectroradiometer (MODIS) for providing them measured data and satellite Images.

\section{References}

[1] R. Duce, "Sources distributions and fluxes of mineral aerosols and their relationship to climate," in Proceedings of the Aerosol Forcing of Climate Conference, pp. 43-72, Berlin, Germany, 1995.

[2] M. O. Andreae, "Climatic effects of changing atmospheric aerosols level," in World Survey of Climatology, A. HendersonSellers, Ed., vol. 16 of Future Climates of the World, pp. 341-392, Elsevier, 1995.

[3] L. Schütz and M. Sebert, "Mineral aerosols and source identification," Journal of Aerosol Science, vol. 18, no. 1, pp. 1-10, 1987.

[4] A. S. Goudie and N. J. Middleton, "Saharan dust storms: nature and consequences," Earth-Science Reviews, vol. 56, no. 1-4, pp. 179-204, 2001.

[5] H. von Suchodoletz, B. Glaser, T. Thrippleton et al., "The influence of Saharan dust deposits on La Palma soil properties (Canary Islands, Spain)," Catena, vol. 103, pp. 44-52, 2013.

[6] M. O. Andreae, B. E. Anderson, D. R. Blake et al., "Influence of plumes from biomass burning on atmospheric chemistry over the equatorial and tropical south Atlantic during CITE 3," Journal of Geophysical Research, vol. 99, no. 6, 1994.

[7] N. M. Mahowald, S. Engelstaedter, C. Luo et al., "Atmospheric iron deposition: global distribution, variability, and human perturbations," Annual Review of Marine Science, vol. 1, pp. 245278, 2009.

[8] K. H. Coale, K. S. Johnson, S. E. Fitzwater et al., "A massive phytoplankton bloom induced by an ecosystem-scale iron fertilization experiment in the equatorial Pacific Ocean," Nature, vol. 383 , no. 6600 , pp. 495-501, 1996.

[9] J. H. Martin and S. E. Fitzwater, "Iron deficiency limits phytoplankton growth in the north-east pacific subarctic," Nature, vol. 331, no. 6154, pp. 341-343, 1988.
[10] W. G. N. Slinn, "Predictions for particle deposition to vegetative canopies," Atmospheric Environment, vol. 16, no. 7, pp. 17851794, 1982.

[11] W. Ruijgrok, C. I. Davidson, and K. W. Nicholson, "Dry deposition of particles: implications and recommendations for mapping of deposition over Europe," Tellus B, vol. 47, no. 5, pp. 587-601, 1995.

[12] N. A. Fuchs, The Mechanics of Aerosols, Pergamon Press, New York, NY, USA, 1964.

[13] G. A. Kallio and M. W. Reeks, "A numerical simulation of particle deposition in turbulent boundary layers," International Journal of Multiphase Flow, vol. 15, no. 3, pp. 433-446, 1989.

[14] L. J. Forney and L. A. Spielman, "Deposition of coarse aerosols from turbulent flow," Journal of Aerosol Science, vol. 5, no. 3, pp. 257-271, 1974.

[15] F. Giorgi, "Dry deposition velocities of atmospheric aerosols as inferred by applying a particle dry deposition parameterization to a general circulation model," Tellus B, vol. 40, no. 1, pp. 23-41, 1988.

[16] L. Zhang, S. Gong, J. Padro, and L. Barrie, "A size-segregated particle dry deposition scheme for an atmospheric aerosol module," Atmospheric Environment, vol. 35, no. 3, pp. 549-560, 2001.

[17] C. S. Zender, H. Bian, and D. Newman, "Mineral Dust Entrainment and Deposition (DEAD) model: description and 1990s dust climatology," Journal of Geophysical Research D, vol. 108, no. 14, pp. 1-19, 2003.

[18] K. Peters and R. Eiden, "Modelling the dry deposition velocity of aerosol particles to a spruce forest," Atmospheric Environment A, vol. 26, no. 14, pp. 2555-2564, 1992.

[19] I. Tegen and I. Fung, "Modeling of mineral dust in the atmosphere: sources, transport, and optical thickness," Journal of Geophysical Research, vol. 99, no. 11, pp. 22897-22914, 1994.

[20] Y. Shao, A. H. Fink, and M. Klose, "Numerical simulation of a continental-scale Saharan dust event," Journal of Geophysical Research, vol. 115, no. 13, 2010.

[21] Y. Shao, K.-H. Wyrwoll, A. Chappell et al., "Dust cycle: an emerging core theme in Earth system science," Aeolian Research, vol. 2, no. 4, pp. 181-204, 2011.

[22] M. D. Gelado-Caballero, P. López-García, S. Prieto, M. D. Patey, C. Collado, and J. J. Hérnndez-Brito, "Long-term aerosol measurements in Gran Canaria, Canary Islands: particle concentration, sources and elemental composition," Journal of Geophysical Research D, vol. 117, no. 3, Article ID D03304, 2012.

[23] M. D. Gelado, M. J. Rodríguez, J. J. Hernández et al., Dust Deposition Fluxes to Northeastern Subtropical Atlantic (Canary Islands), Universidad de las Palmas de Gran Canaria, Gran Canaria, Spain, 2004.

[24] S. Palarya, Air Pollution Meteorology and Dispersion, Oxford University Press, New York, NY, USA, 1999.

[25] S. Nickovic, G. Kallos, A. Papadopoulos, and O. Kakaliagou, "A model for prediction of desert dust cycle in the atmosphere," Journal of Geophysical Research D, vol. 106, no. 16, pp. 1811318129, 2001.

[26] P. Knippertz and A. H. Fink, "Synoptic and dynamic aspects of an extreme springtime Saharan dust outbreak," Quarterly Journal of the Royal Meteorological Society, vol. 132, no. 617, pp. 1153-1177, 2006.

[27] H. J. Beine, A. Amoroso, G. Esposito et al., "Deposition of atmospheric nitrous acid on alkaline snow surfaces," Geophysical Research Letters, vol. 32, no. 10, Article ID L10808, pp. 1-4, 2005. 
[28] L. Tositti, A. Riccio, S. Sandrini et al., "Short-term climatology of PM10 at a high altitude background station in southern Europe," Atmospheric Environment, vol. 65, pp. 142-152, 2013.

[29] G. Kallos, “The regional weather forecasting system SKIRON: a general overview," in Proceedings of the Symposium on Regional Weather Prediction on Parallel Computer Environments, Athens, Greece, 1997.

[30] S. Nickovic, D. Jovic, O. Kakaliagou, and G. Kallos, "Production and long-range transport of desert dust in the Mediterranean region: Eta model simulations," in Proceedings of the 22nd NATO/CCMS International Technical Meeting on Air Pollution Modeling and Its Applications, Clermont-Ferrand, France, 1997.

[31] S. Nickovic, G. Kallos, A. Papadopoulos, and O. Kakaliagou, "A model for prediction of desert dust cycle in the atmosphere," Journal of Geophysical Research D, vol. 106, no. 16, pp. 1811318129, 2001.

[32] A. Arakawa, "Design of the UCLA general circulation model. Numerical Simulation of Weather and Climate," Tech. Rep. 7, Department of Meteorology, University of California, LA, Calif, USA, 1972.

[33] S. A. Slinn and W. G. N. Slinn, "Predictions for particle deposition on natural waters," Atmospheric Environment A, vol. 14, no. 9, pp. 1013-1016, 1980.

[34] F. Giorgi, "A particle dry deposition parameterization scheme for use in tracer transport models," Journal of Geophysical Research, vol. 91, pp. 9794-9806, 1986.

[35] T. N. Carlson and S. G. Benjamin, "Radiative heating rates for Saharan dust," Journal of the Atmospheric Sciences, vol. 37, no. 1, pp. 193-213, 1980.

[36] J. M. Prospero, "Long-range transport of mineral dust in the global atmosphere: impact of African dust on the environment of the southeastern United States," Proceedings of the National Academy of Sciences of the United States of America, vol. 96, no. 7, pp. 3396-3403, 1999.

[37] I. Tegen, "Modeling the mineral dust aerosol cycle in the climate system," Quaternary Science Reviews, vol. 22, no. 18-19, pp. 18211834, 2003.

[38] P. Sancho, J. De La Cruz, A. Diaz et al., "A five-year climatology of back-trajectories from the Izana baseline station, Tenerife, Canary islands," Atmospheric Environment A, vol. 26, no. 6, pp. 1081-1096, 1992.

[39] P. Dorta, M. D. Gelado, P. Cardona et al., "Algunas consideraciones sobre la importancia del polvo de origen sahariano en el clima del archipielago canario y su aporte a las aguas superficiales oceanicas," in Publicaciones de la AEC, pp. 13-24, El agua y el clima, Palma de Mallorca, Spain, 2002.

[40] N. G. Prezerakos, S. C. Michaelides, and A. S. Vlassi, "Atmospheric synoptic conditions associated with the initiation of north-west African depressions," International Journal of Climatology, vol. 10, no. 7, pp. 711-729, 1990.

[41] K. W. Nicholson, "The dry deposition of small particles: a review of experimental measurements," Atmospheric Environment, vol. 22, no. 12, pp. 2653-2666, 1988.

[42] P. Dorta, M. D. Gelado, and J. J. Hemandez, "Frecuencia, estacionalidad y tendencias de las advecciones de aire shariano en Canarias (1976-2003)," in Investigaciones Geograficas, vol. 38, pp. 23-45, Instituto Universitario de Geografia. Universidad de Alicante, 2005.

[43] S. Alonso-Pérez, E. Cuevas, and X. Querol, "Objective identification of synoptic meteorological patterns favouring African dust intrusions into the marine boundary layer of the subtropical eastern north Atlantic region," Meteorology and Atmospheric Physics, vol. 113, no. 3, pp. 109-124, 2011.

[44] R. Ausra, "Aerosol deposition to coastal forests: a wind tunnel approach," Dissertations 43/2011, Linnaeus University, 2011.

[45] Y. Shao, Physics and Modelling of Wind Erosion, Springer, Berlin, Germany, 2 edition, 2008.

[46] Y. Toba, "On the giant sae-salt particles in the atmosphere-II Theory of the vertical distribution in the layer $10 \mathrm{~m}$ over the Ocean," Tellus, vol. 17, pp. 365-382, 1965.

[47] A. Petroff, L. Zhang, S. C. Pryor, and Y. Belot, "An extended dry deposition model for aerosols onto broadleaf canopies," Journal of Aerosol Science, vol. 40, no. 3, pp. 218-240, 2009.

[48] M. Rashidi, G. Hetsroni, and S. Banerjee, "Particle-turbulence interaction in a boundary layer," International Journal of Multiphase Flow, vol. 16, no. 6, pp. 935-949, 1990.

[49] N. B. Wood, "A simple method for the calculation of turbulent deposition to smooth and rough surfaces," Journal of Aerosol Science, vol. 12, no. 3, pp. 275-290, 1981.

[50] F. Giorgi, "A particle dry deposition parameterization scheme for use in tracer transport models," Journal of Geophysical Research, vol. 91, pp. 9794-9806, 1986.

[51] G. Kallos and P. Katsafados, Desert Dust Uptake-Transport and Deposition Mechanisms-Impacts of Dust on Radiation, Clouds and Precipitation, Fluid Mechanics of Environmental Interfaces, Taylor and Francis e-Library, 2008.

[52] K. A. Rahn, "Silicon and aluminum in atmospheric aerosols: crust air fractionation?" Atmospheric Environment, vol. 10, no. 8, pp. 597-601, 1976.

[53] J. M. Martin and M. Withfield, "The significance of the river input of chemical elements to the ocean," in Traces Metals in Sea Water, C. S. Wong, Ed., pp. 265-296, Plenum, New York, NY, USA, 1983.

[54] C. Guieu, M.-D. Loÿe-Pilot, C. Ridame, and C. Thomas, "Chemical characterization of the Saharan dust end-member: some biogeochemical implications for the western Mediterranean Sea," Journal of Geophysical Research D, vol. 107, no. 15, pp. 1$11,2002$.

[55] L. Schütz, R. Jaenicke, and H. Petrick, "Saharan dust transport over the North Atlantic Ocean," in Desert Dust: Origin, Characteristics and Effect on Man, T. L. Péwé, Ed., pp. 87-100, Geological Society of America, 1981.

[56] G. Bergametti, Apports de matière par voie atmosphérique à la Méditerranée occidentale: aspects géochimiques et météorologiques [Ph.D. dissertation], Université Paris VII, 1987.

[57] K. Pye, Aeolian Dust and Dust Deposition, Academic Press, London, UK, 1987.

[58] N. Kubilay, S. Nickovic, C. Moulin, and F. Dulac, "An illustration of the transport and deposition of mineral dust onto the eastern Mediterranean," Atmospheric Environment, vol. 34, no. 8, pp. 1293-1303, 2000.

[59] I. Menéndez, J. L. Díaz-Hernández, J. Mangas, I. Alonso, and P. J. Sánchez-Soto, "Airborne dust accumulation and soil development in the North-East sector of Gran Canaria (Canary Islands, Spain)," Journal of Arid Environments, vol. 71, no. 1, pp. 57-81, 2007. 

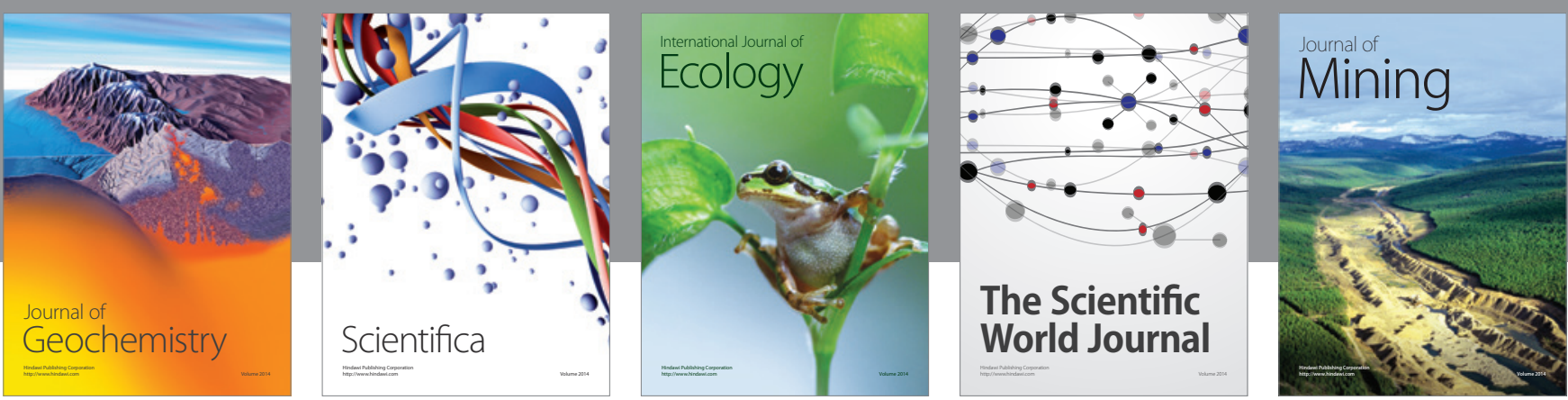

The Scientific World Journal
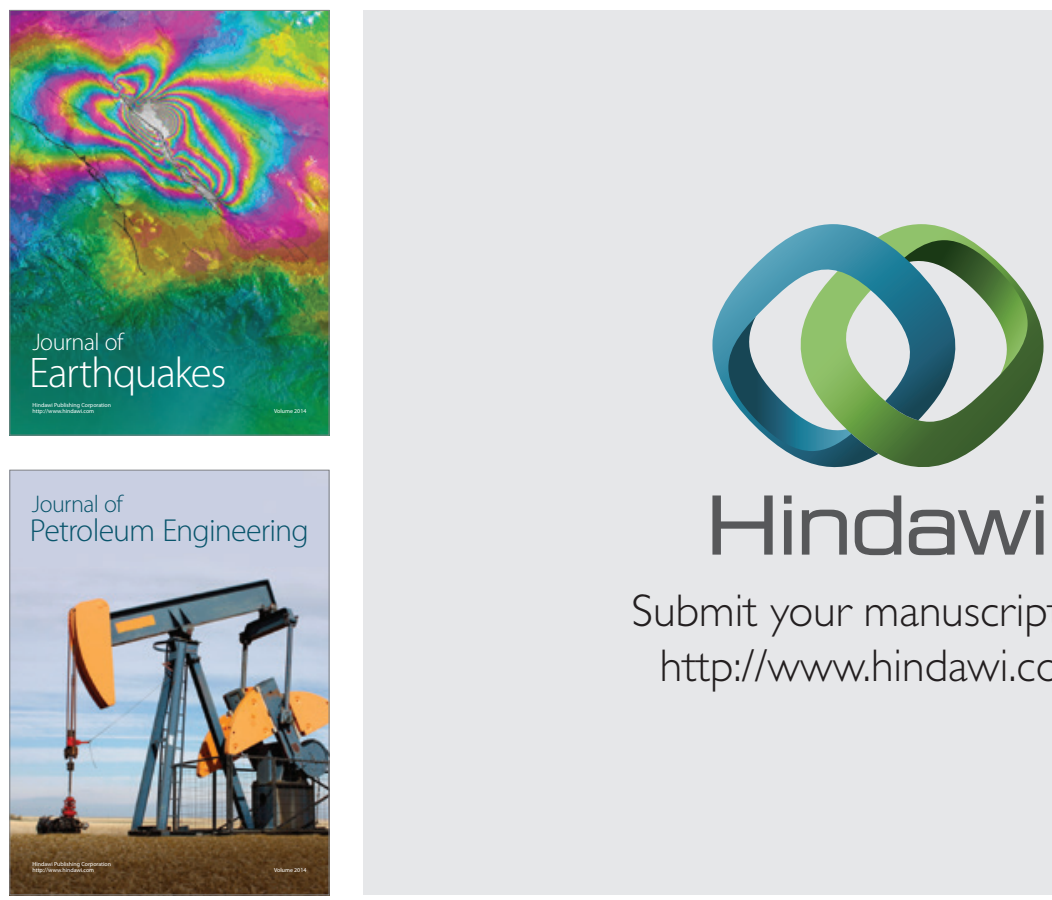

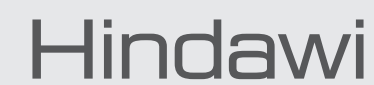

Submit your manuscripts at

http://www.hindawi.com
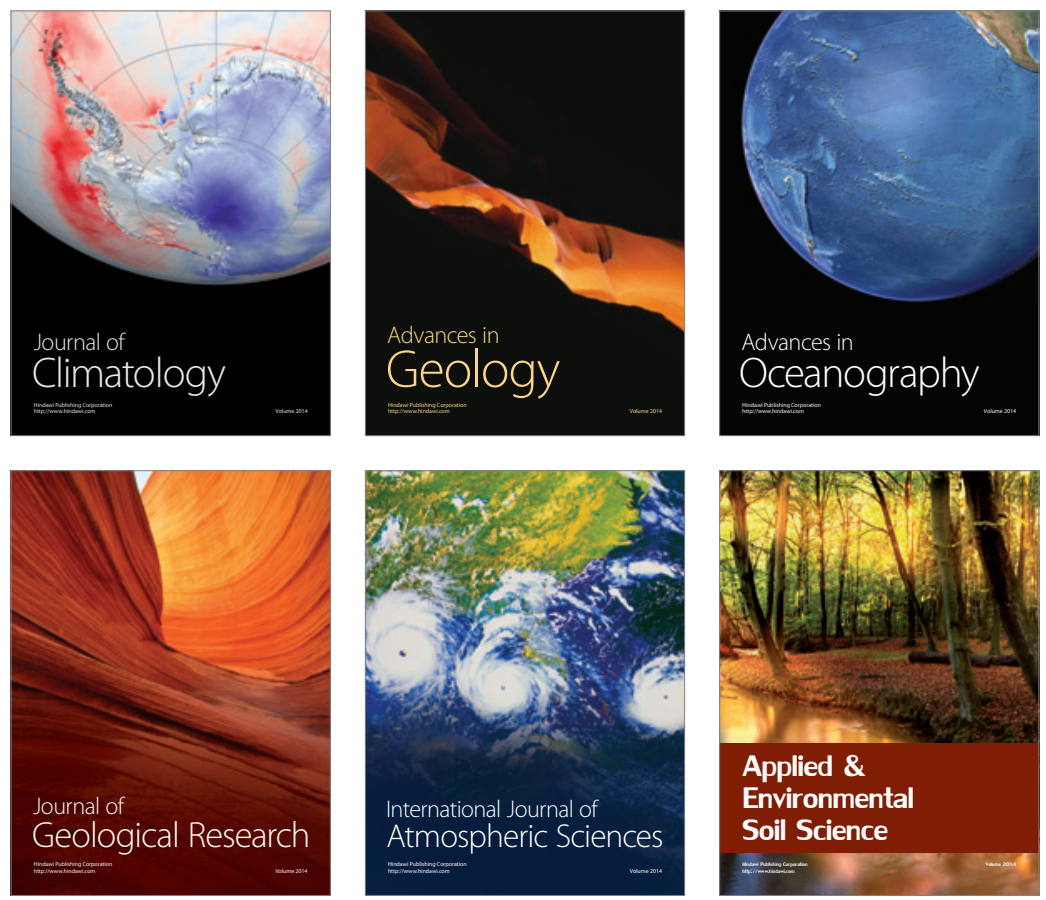
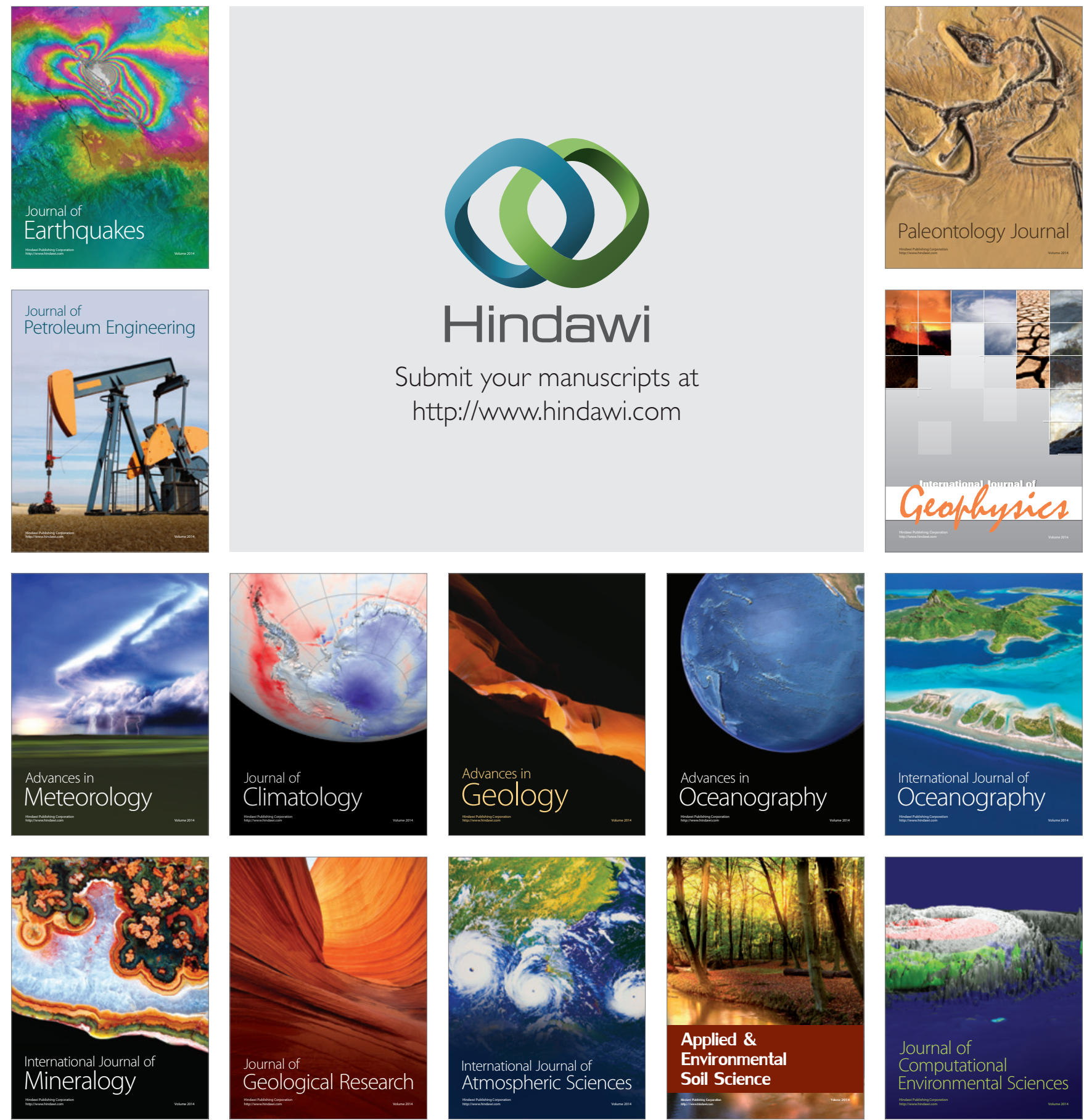